\title{
TECTÓNICA DE PLACAS Y VULCANISMO EN EL ÁREA DE DEL GRAN RIFT
}

\author{
plate tectonics and volcanism in the Great Rift zone \\ Jean Pierre Bergoeing*
}

\section{Resumen}

El autor, a trawés de dacumentos científicos diwersos, imágenes satelitales y algunas fotos ilustra el wulcanismo de ung de los sectores tectónicos más activos del planeta, dando una explicación de este sector particular del Africa oriental.

Palavras-chave: Acreción, Placas tectónicas, dorsales, basaltos, traquitas.

\begin{abstract}
The author, across research documents, satellite images and some photos illustrates the wolcanism of one of the most active tertonic sectors of the planet, giving an explanation of this particular area of Eastern Africa. Keywords: Accretion, Tectonic plates, dorsal margin, basalts, trachytes.

\section{Résumé}

L'auteur à trayers divers documents scientifiques, images satellitaires et quelques photos, illustre le valcanisme d'une des régions les plus actives de la planète, donnant une explication de ce secteur particulier de l'Afrique orientale.

Mots-Clés: Accrétion, Plaques tectoniques, dorsales, basaltes, trachytes.
\end{abstract}

(*) Prof De Catedrático da Universidad de Costa Rica- San Pedra Montes de Oca, San José, Costa Rica, Tel: (+00) 506.86.29.07.12 - jegadana $(\alpha$ gmail.com 


\section{INTRODUCCIÓN}

El sector del África oriental es el resultado del accidente tectónico del Gran Rift, fractura mayor que corta el continente de norte a sur. En esta zona es donde el continente se separa en sentidos opuestos: el magma ha hecho extrusión, formando poderosos conos volcánicos y mesetas dejando profundas depresiones lacustres que caracterizan el paisaje actual donde las poblaciones se han asentado y en donde subsiste aún una gran variedad de fauna salvaje. (Figura 1).

El Gran Rift africano es la expresión morfológica de un Rift magmático cuya actividad comenzó hace unos 30 millones de afios en el Afar, evolucionando hacia el Sur donde muchos centros de emisión nacieron hasta alcanzar la extremidad Sur del Rift Kenyano hace unos 8 millones de afios en donde el Rift se divide en tres ramas divergentes (Eyasi, Natrón-Manyara y Panganii).

En el sistema Pangani las deformaciones son menos evidentes y dominadas por un sistema de bloques basculados donde se ha creado una cordillera volcánica neogena cuya orientación es Este-Oeste que cubre unos $200 \mathrm{~km}$ y donde emergen los conos del Ngorongoro, Meru y Kilimanjaro.

El valle tectónico del Gran Rift es el elemento geológico mayor del Africa Oriental. Se extiende desde el sur del mar Rojo hasta el río Zambeze recorriendo más de $9.500 \mathrm{~km}$ de longitud. Tiene un ancho promedio de $40 \mathrm{a} 60 \mathrm{~km}$ y su profundidad varia de los cientos a los miles de metros. Es un sector tectónico constituido por fallas normales que se producen a partir del Mioceno. La subsidencia está rellenada por sedimentación lacustre e inmensos lagos (Kivu, Tanganyika, Malawi). La expansión del Rift es del orden de 10 milímetros a 12 centímetros por afio, disminuyendo hacia el sur. Los montes Kilimanjaro y Kenia se sitúan en la intersección oriental del alineamiento tectónico. Según Tom Wright, geofisico inglés, el análisis de imágenes tomadas por el satélite Envisat de la Agencia Espacial Europea (ESA) permite confirmar cómo esta porción de tierra africana se ha ido separando gradualmente, al ritmo de 12 centímetros por afio.

El Gran Rift se inicia en Asia, en el río Jordán. Desde ahí forma una dorsal a través del mar Rojo separando las costa de Egipto y Sudán de las costas de la península Arabe. El mar Rojo recorre unos $1977 \mathrm{~km}$ desde el golfo de Akaba hasta Bab-el Mandeb. Tiene un ancho máximo de $300 \mathrm{~km}$ y una profundidad que llega hasta los 2.500 metros pero la profundidad media no supera los 500 metros. En ambas márgenes encontramos las trazas de un antiguo volcanismo basáltico que se inició en el Mioceno. Igualmente gracias a las imágenes de Google Earth 2010, es posible observar una serie de estructuras tectónicas y volcánicas producto de la zona de acreción en el Estrecho de Bab-el-Mandeb ( Las puertas del infiemo o las puertas de las lágrimas) que separan el mar Rojo del Océano Indico a través del golfo de Adén. Este sector es uno de los grandes accidentes tectónicos del planeta ya que marca la separación entre la placa de la península Árabe y la placa Africana, por una parte y el inicio del Gran Rift Africano a partir del sector Yibuti-Etiopía.

El Africa Oriental se caracteriza por situarse en una zona tectónica de gran inestabilidad conocida como el gran Rift. Se trata de un lugar donde tres placas tectónicas divergen permitiendo la ascensión magmática y la construcción de volcanes importantes. El sector oriental dentro de unos millones de afios se separará dando origen a un nuevo continente, tal y como lo hizo ya la isla de Madagascar. El punto triple del Afar es el punto de contacto de tres placas tectónicas; Árabe, Nubia y Somalí. Estas fronteras corresponden a dos dorsales oceánicas (Mar Rojo y Golfo de Adén y el Rift continental africano). Este sector se caracteriza por tener magmas alcalinos que tienen su origen en zonas profundas asociados al desarrollo de aperturas de Rift continentales. Las rocas más características son los basaltos alcalinos, siendo usual la presencia de términos evolucionados (traquitas y fonolitas). El volcán Dubbi en Eritrea, es un buen ejemplo de ello. 


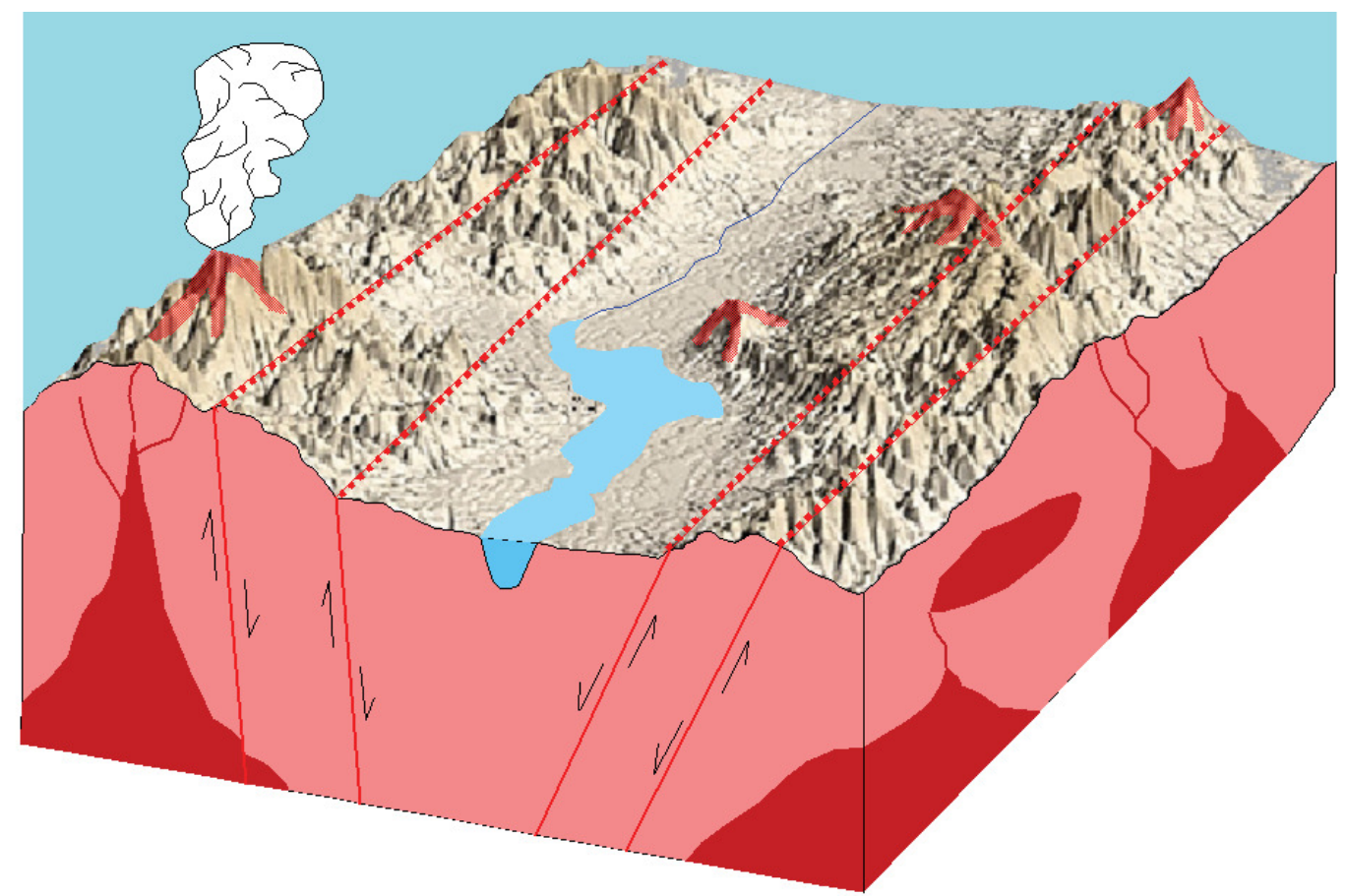

Figura 1 - Graben del Gran R ift formado por la acreción de las placas tectónicas africana y somalí. Modelo de J.P. Bergoeing. Creación de Osear Barrientos.

\section{LA VERTIENTE ÁRABE DE LA DORSAL DEL MAR ROJO}

\section{Tectónica y Vulcanismo de la Península Árabe}

La costa oriental del Mar Rojo es un reflejo del inicio del área de acreción que se prolonga por miles de kilómetros hacia el sur, dando nacimiento al Gran Rift Africano (Figura 2). En el sector peninsular Árabe, aparecen edificios volcánicos bien conservados, de la actividad que se inicia a comienzos del Plioceno y se prolonga de muestros días.

Es un sector desértico, donde los paisajes de dunas recubren gran parte del relieve, sin embargo algunas grandes estructuras volcánicas se han conservado y desde el aire se pueden observar las grandes coladas de lava que emergen de un punto central que es el centro de emisión

El Campo volcánico de Harrat Khaybar (Figuras 2 y 3 ) situado en $25^{\circ}$ lat. N. y $40^{\circ}$ long. E. es una de las zonas volcánicas más extensas del la península Arabe. Data de comienzos del Plioceno y con actividad verificada hasta el el afio 650 de nuestra era. Cubre una superficie de $14.000 \mathrm{~km}^{2}$ y culmina a $2093 \mathrm{~m}$ en el domo Jabal Abyad. Forma parte de un alineamiento volcánico de más de $600 \mathrm{~km}$ compuesto por varios edificios de volcanes escudos coalescentes donde sobresale el estrato-volcén del Jabal Quidr, domos y coladas, Algunos sitios neoliticos están recubiertos por coladas de lava. (http:/www.activolcans.info/volcan-HarratKhaybar.html). 


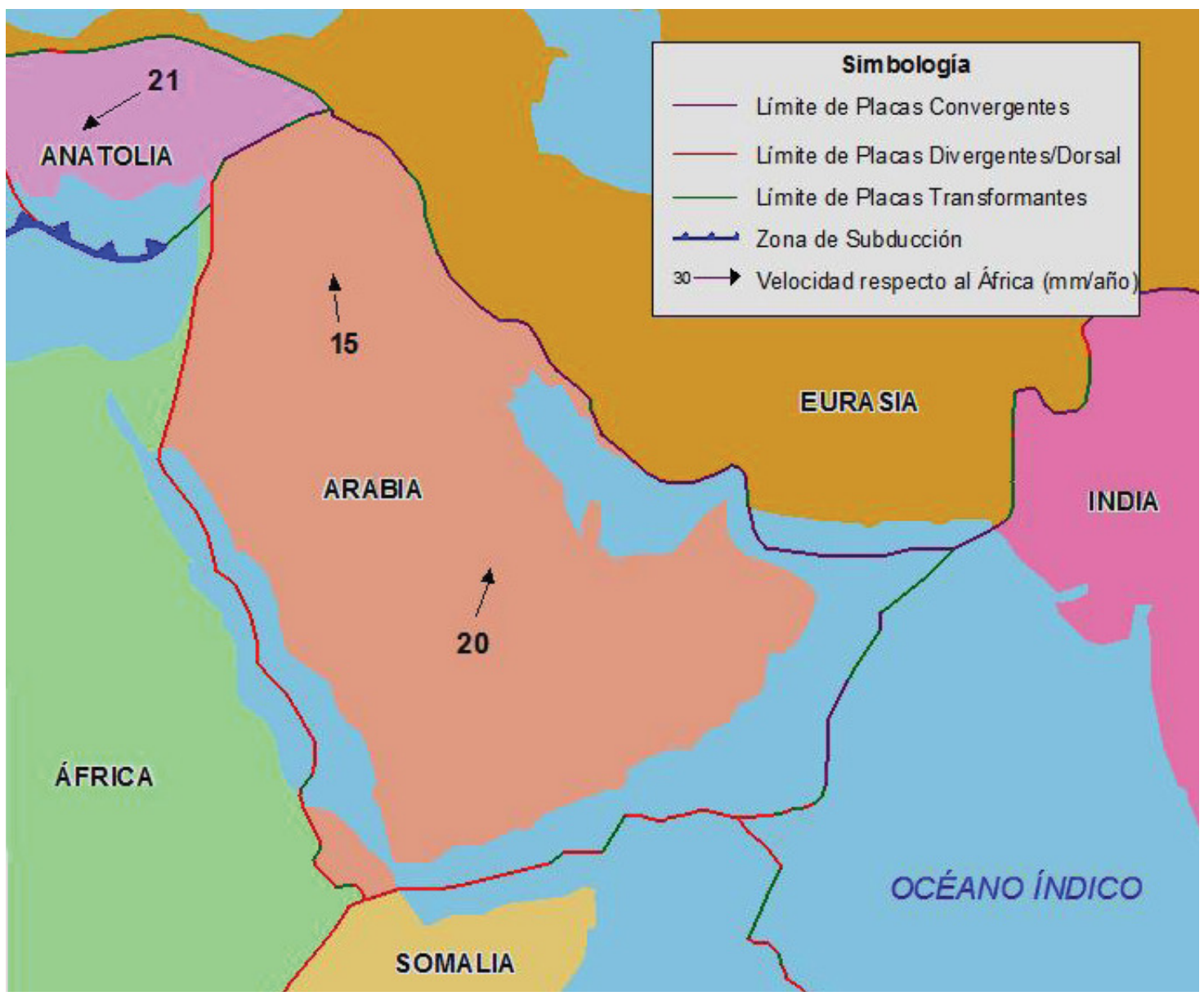

Figura 2 - Placas tectónicas del sector del Gran Rift entre Africa y Asia modificado de "Earth of fire"
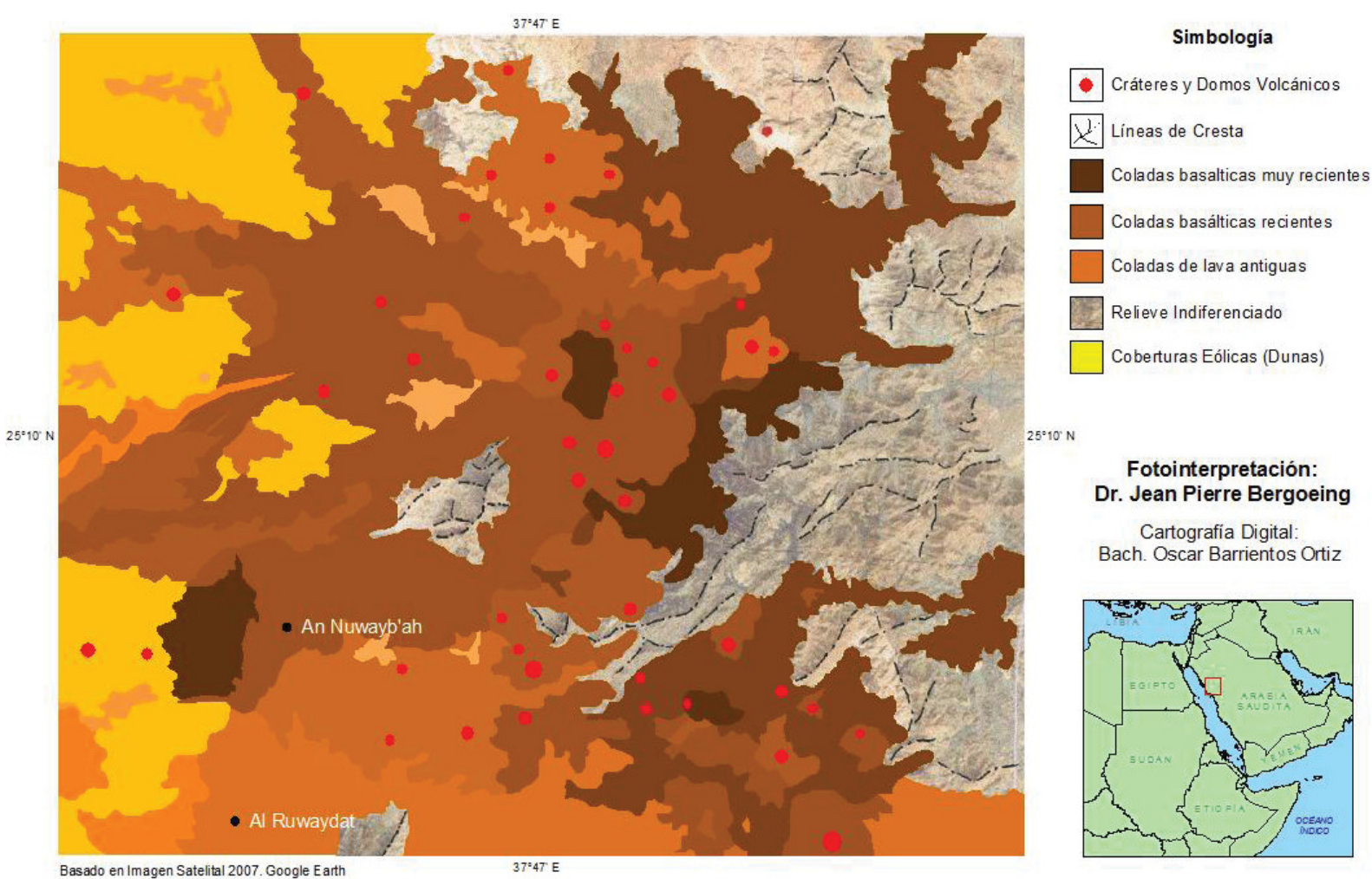

Fotointerpretación: Dr. Jean Pierre Bergoeing

Cartografia Digital Bach. Oscar Barrientos Ortiz

Figura 3 - Campo volcánico de Harrat Khaybar recubierto por lavas basálicas al norte de Medina en Arabia Saudita, cercano al poblado de An Nuwayb"ah, compuesto por una serie de conos volcánicos de donde se originó una profusión de coladas basálticas hacia el oeste. Fotointerpretación basada en imagen satelital Google 2011. 
Otro campo volcánico, en el mismo sector de coordenadas geográficas, conocido como Harrat Lunayyir (Figura 4) forma parte de la provincia volcánica de la costa oeste de Arabia Saudita y cubre una superficie de de $180.000 \mathrm{~km}^{2}$ en Arabia Saudita y se sitúa próximo a la ciudad de Medina a unos $200 \mathrm{~km}$ del mar Rojo, lo que viene a demostrar la influencia de la dorsal del mar Rojo hasta este punto. De abril a junio 2009 se registró un enjambre sísmico de 4 a 5.7 grados en la escala de Richter que hizo temer una posible erupción volcánica y por ello más de 40.000 personas fueron evacuadas, Durante este periodo una falla de $3 \mathrm{~km}$ se expandió en $8 \mathrm{~km}$ durante el sismo más importante que alcanzó los 5.7 grados. Es te sector que se remonta al Mioceno era considerado como inactivo hasta ese momento.

El análisis de los sismos permitieron determinar que se trata de una ascensión magmática de lava fluida (basaltos) que se sitúa a lo largo de la falla mencionada ( JONSSON et al. 2009)

\section{El Estrecho de Bab-el-Mandeb}

El sector propio del estrecho de Bab-el- Mandeb está constituido por un pequefio archipiélago des islas volcánicas (islas Hanish) expresión del accidente tectónico del Mar Rojo, que dará origen por una parte al Gran Rift africano que se origina a partir de Yibutí (en esta úl tima región se encuentra el punto más bajo de toda África, el lago Assal, a 155 metros bajo el nivel del mar), y por otra parte a un sistema tectono-volcánico que se dibuja sobre las costas meridionales de Yemen, frente al golfo de Adén. El estrecho tiene unos $115 \mathrm{~km}$ de longitud, aunque en su parte más angosta, a veces considerada exclusivamente el propio estrecho, tiene menos de $30 \mathrm{~km}$ de ancho(isla Perim), desde Ras Menheli, en la costa árabe, a Ras Siyan en Africa

El Djebel Al-Tair es un volcán insular que se localiza en el mar Rojo entre $15.55^{\circ}$ de lat. N. y $41,82^{\circ}$ de long. E. Es un volcán parcialmente emergido que alcanza una altitud de $244 \mathrm{~m}$. Emite lavas basálticas ( toleitas). El volcán ha registrado erupciones explosivas en el siglo XVIII y XIX. El 7 de septiembre de 2007, después de una serie de sismos el volcán hizo erupción emitiendo coladas de lavas basálticas que bajaron por los flancos de su cono hasta el mar y haciendo víctimas entre los soldados de la dotación yemenita apostada en ese lugar.( http:/www.activolcans.info/ volcan-Jebe-al-Tair.html)

\section{Los Volcanes de la Dorsal del Golfo de Adén}

Hacia el este, en Adén una fractura tectónica importante se dibuja a lo largo de la costa sur de la península Árabe. Esta fractura está asociada a la del Afar. Consecuencia de ello son los volcanes que se formaron en este sector y que igualmente son de tipo basáltico. La ciudad de Adén está edificada sobre estas estructuras volcánicas.

La costa sur del Yemen entre Bab-el Mandeb y Adén se caracteriza por ser un área tectónica de acreción donde las placas de Arabia y de Somalia se encuentran formando

Una dorsal submarina. Consecuencia de ello existen seis centros de emisión volcánicos que se remontan al Mioceno-Plioceno. En el sector donde está construido el puerto de Adén existen tres estructuras volcánicas muy erosionadas que son los volcanes de Adén, Pequefio Adén y Ras Imnrán. Su avanzado grado de erosión permite hacer un estudio detallado de ellos. Están compuestos por basal to traquitas y riolitas. Los volcanes se caracterizaron por un periodo de calderas de explosión donde el volcán emitió traqui-andesitas, traquitas y riolitas alcalinas. En su última fase eruptiva los volcanes emitieron entre otros productos olivino toleitico.

La imagen satelital Google permite observar que geomorfologicamente los volcanes se encuentran muy erosionados conservando parte de su cono que conforma un gran rim. El cono está entallado por numerosas quebradas que han indo evolucionando propio al medio árido creando profundas quebradas. Al oeste del cráter de Adén se vislumbra un pequeño cráter en forma de media luna. Y al este lo que queda de un cráter sumergido (Figura 5). Parte de la ciudad de Adén se encuentra edificada al interior del cráter. Los tres volcanes alineados en dirección oeste-este se 


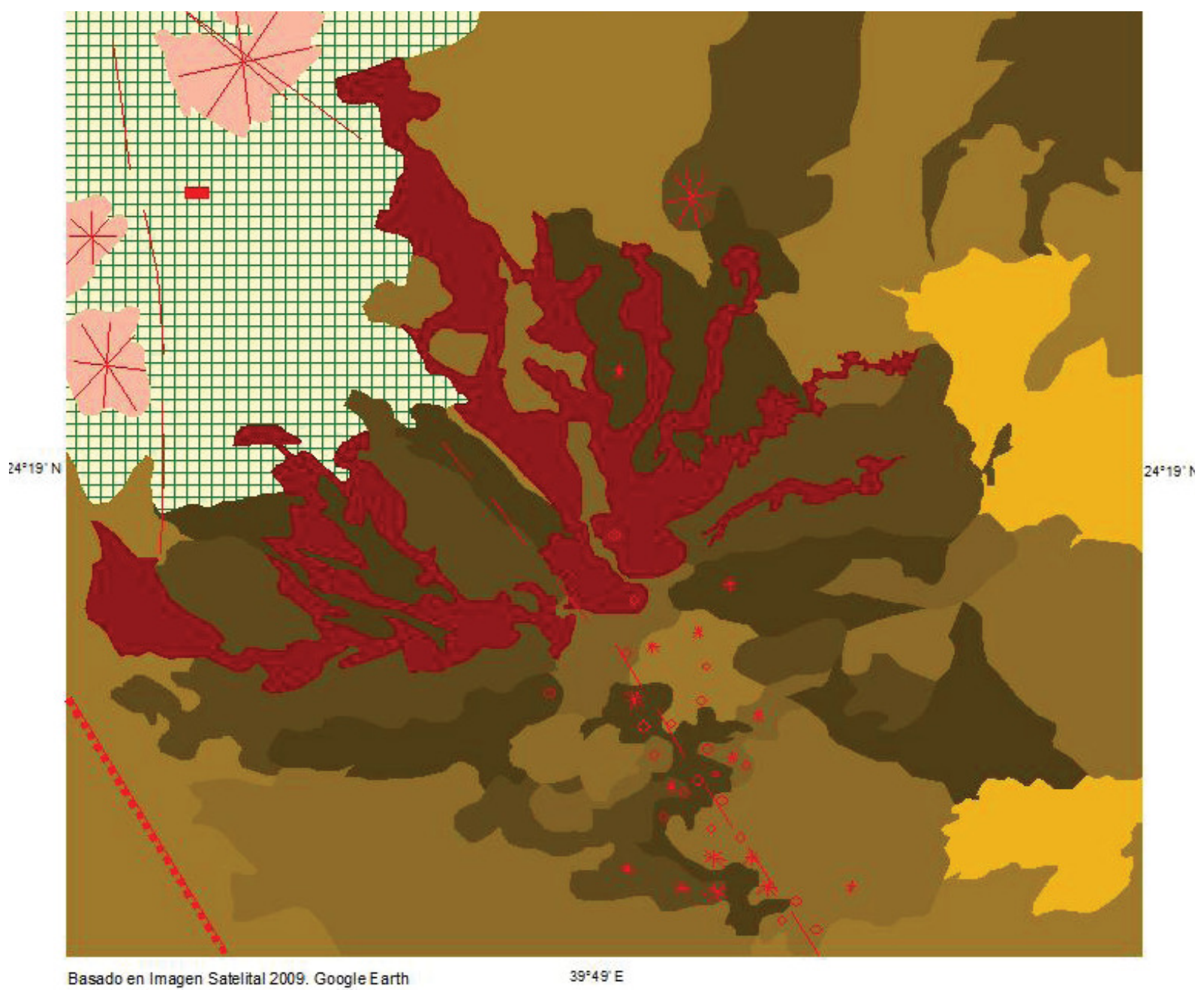

Fotointerpretación: Dr. Jean Pierre Bergoeing

\section{Simbología}

Cartografia Digital: Bach. Oscar Barrientos Ortiz
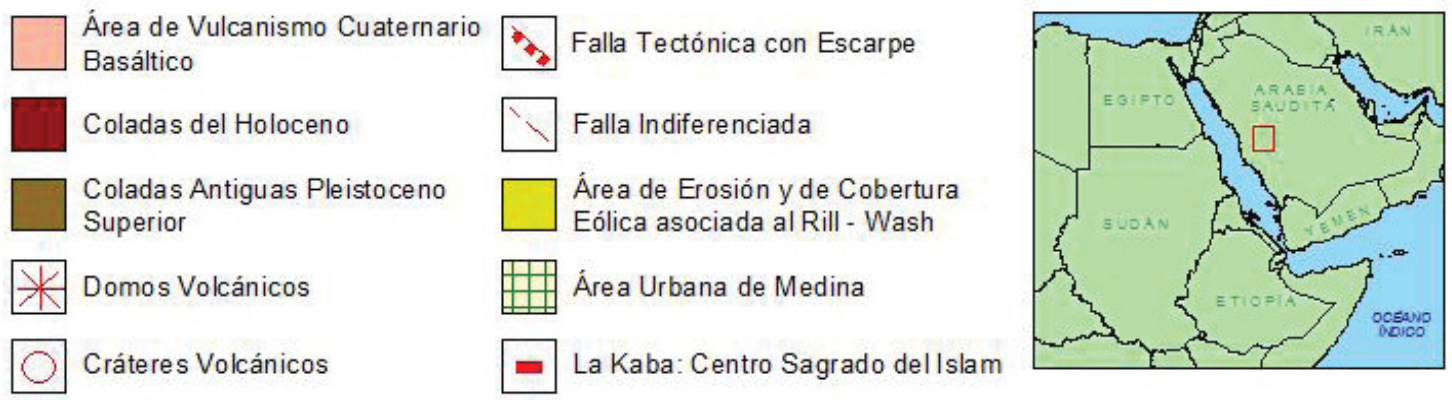

Figura 4 - Campo voleánico de Medina. Arabia Saudita. 
unieron al continente, probablemente durante el Cuaternario mediante flechas litorales, producto de la erosión continental

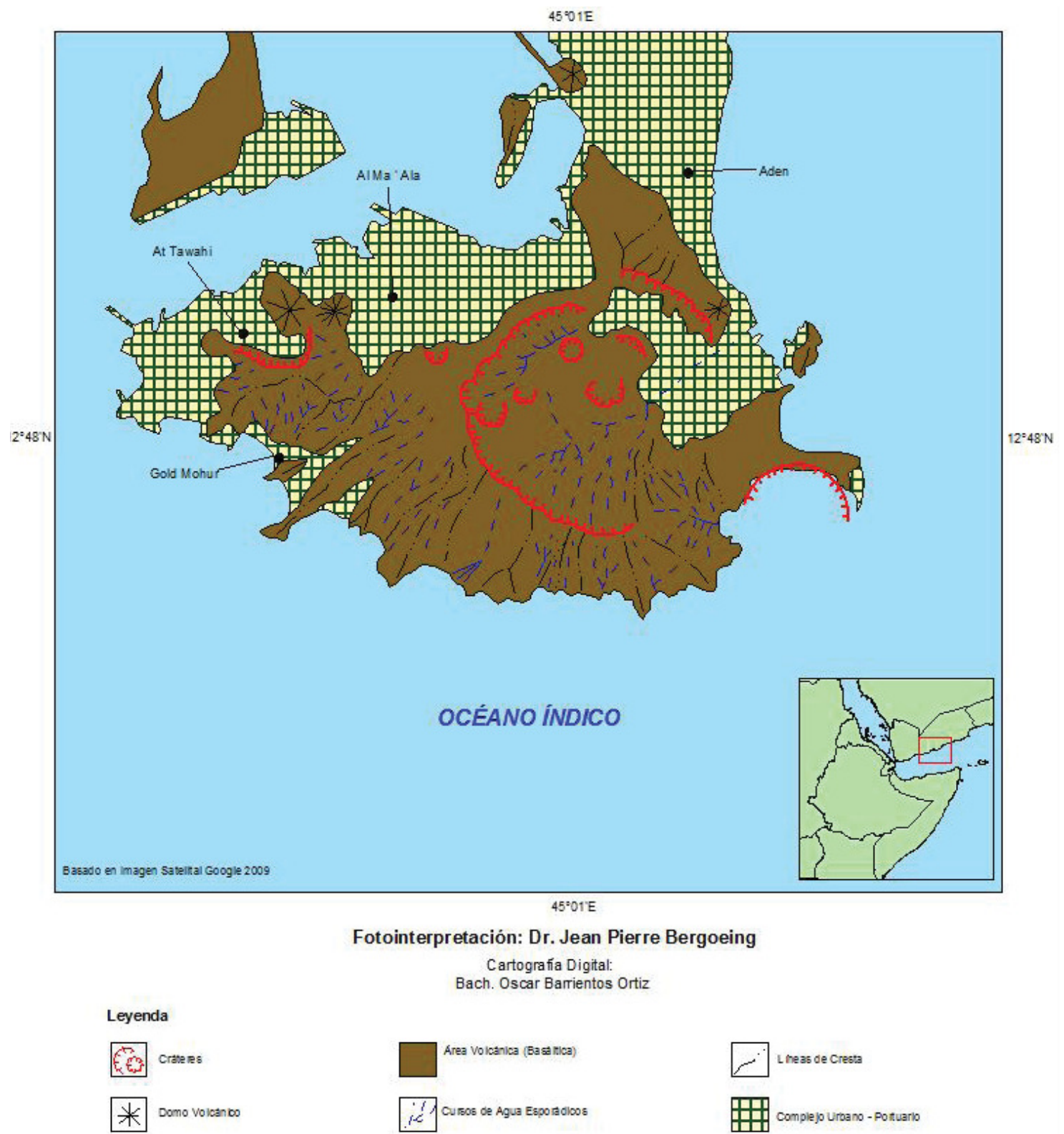

Figura 5 - Cráter de Adén ocupado en parte por la edificación urbana de la ciudad portuaria. Al oeste emerge un cono desbocado (A1 Tawahi) y al este una caldera cuyo borde conforma un promontorio. (Interpretación de una. imagen satelital Google 2010)

Adén es un puerto situado al este del estrecho de Bab-el Mandeb construido sobre viejas estructuras volcánicas y que fue ocupado por los hombres desde el Siglo VII a.C. Está compuesto por varios centros urbanos; el puerto, la ciudad industrial conocida como (pequefio Adén) con su gran refinería de petróleo y Madinat ash Sha'b que es el centro del gobiemo administrativo. Posee dos suburbios Khormaksar y Sheikh Othman, que unen el norte de la ciudad vieja con el aeropuerto internacional. (Figura 5) Por su posición estratégica entre la India y el canal de Suez que le confieren una importancia comercial y estratégica de primer orden. El almirante chino Zheng He hizo escala en Adén en 1421 en su viaje transoceánico. En 1538 pasó bajo soberanía Otomana y en 1838 forma parte del Imperio colonial británico hasta su independencia en 1967. 


\section{Primeras Estructuras Volcánicas del Rift entre Egipto, Sudán y Eritrea, en la Margen Africana de la Dorsal del Mar Rojo}

\section{La Geología del Sector Nor-Oriental de ÁfricA.}

El sur del desierto de Libia, en Egipto está constituido por un zócalo cristalino formado por elementos graníticos de más de 600 millones de afios (precámbrico) recubierto por sedimentos continentales muy erosionado (Cámbrico a Ordovícico inferior). Durante el Primario un mar tropical, poco profundo, se instala en esta parte del continente que se caracteriza por arcillas y calizas fosiliferas. Las areniscas de Nubia marcan una regresión marina que durará 70 millones de afios. Del devónico al Cretácico el continente forma parte de una masa continental única; la Pangea.

Durante el Cretácico, el mar de Tetys sumerge esta parte de Egipto creando el continente de Gondwana. A finales de este periodo emerge nuevamente el territorio egipcio y a comienzos del Terciario (65 millones de afios) los dinosaurios y amonites han completamente desaparecidos. Durante el Eoceno el mar de Tetys ya no existe y comienza a formarse el Gran Rift con la creación del mar Rojo que se ensancha progresivamente y se crean las grandes depresiones lacustres del Africa oriental. En el norte (Egipto, Nubia), las lluvias modelan cafiones y mesetas, paulatinamente el clima se modifica hasta alcanzar la aridez actual. Es durante el Mioceno que una actividad volcánica comienza a manifestarse y se prosigue durante el Plioceno y se continúa manifestando hasta nuestros dias a partir de Eritrea hacia el sur. Al norte de este punto quedan los remanentes de esta actividad, calderas, cráteres y coladas de basaltos principalmente. Entre la cuarta y sexta catarata del Nilo se extiende el desierto de Bayuda, que se caracteriza por sus rocas negras, basálticas, testimonio de la antigua actividad volcánica de esta zona. Igualmente se encuentra una caldera volcánica en Gebel Abu Nahl que data del pre-cámbrico y es más grande que todos los cráteres conocidos del norte del Sudán.

La Península del Sinaí y el golfo de Aqaba corresponde a un desprendimiento tectónico NE-SW producido por la placa tectónica de Arabia (Figura 6) durante el Plioceno y que da inicio a la dorsal del mar Rojo y el Gran Rift. (Jean Joseph Blanc). Al dirigirse hacia el sur, a partir de Egipto siguiendo la dorsal del Mar Rojo, comienzan a aparecer las primeras estructuras volcánicas del Mioceno-Plioceno. 


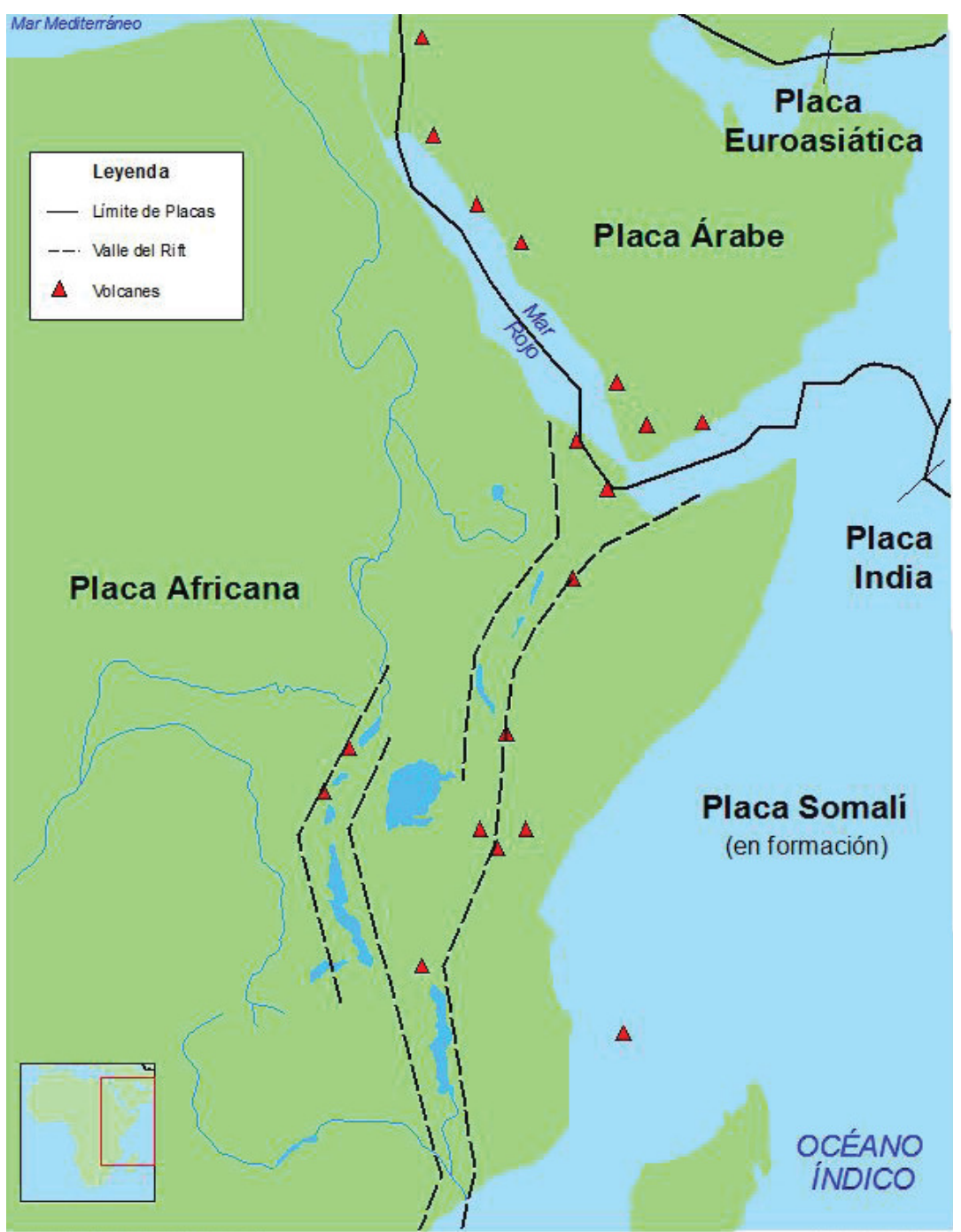

Figura 6 - Gran Rift Africano ( zona de acreción) con la Placa Nubia (Oeste) y la placa Somalí (Este).

\section{LAS ESTRUCTURAS VOLCÁNICAS ACTIVAS DEL RIFT EN ERITREA}

Al sur del Sudán comienza la cordillera del Afar en donde emergen volcanes importantes, como son el Dubi, el Nabro, el Erta Alé y la caldera del Musa Ali.

\section{Volcán Dubbi}

El Dubbi es un estrato volcán activo del sector del Rift Eritreo (Figura 7) que se alarga con una serie de conos por donde una serie de erupciones se han producido. Se trata de largas coladas de lava basáltica. Del Dubbi propiamente tal han emergido cuatro grandes coladas de las cuales la del año 1450 y la de 1861 llegaron hasta el mar Rojo recorriendo una distancia de $22 \mathrm{~km}$.. En 1861 el volcán hizo erupción emitiendo 3.500 millones de metros cúbicos de lava basáltica que salieron de 19 conos volcánicos situados en la cima y sus cenizas se dispersaron en un radio de $250 \mathrm{~km}$. Causó más de 100 victínas en un área desértica que corresponde a la sierra del Danakil. Posee más de 20 conos cineríticos en su cima e innumerables conos parásitos emergen en su base en parte sumergidos por las poderosas coladas de lava que han fluido desde su cima Desde entonces el volcán ha tenido una serie de erupciones. El 13 de junio de 2011 la erupción del Nabro vecino, inicialmente fue atribuida al Dubbi. 


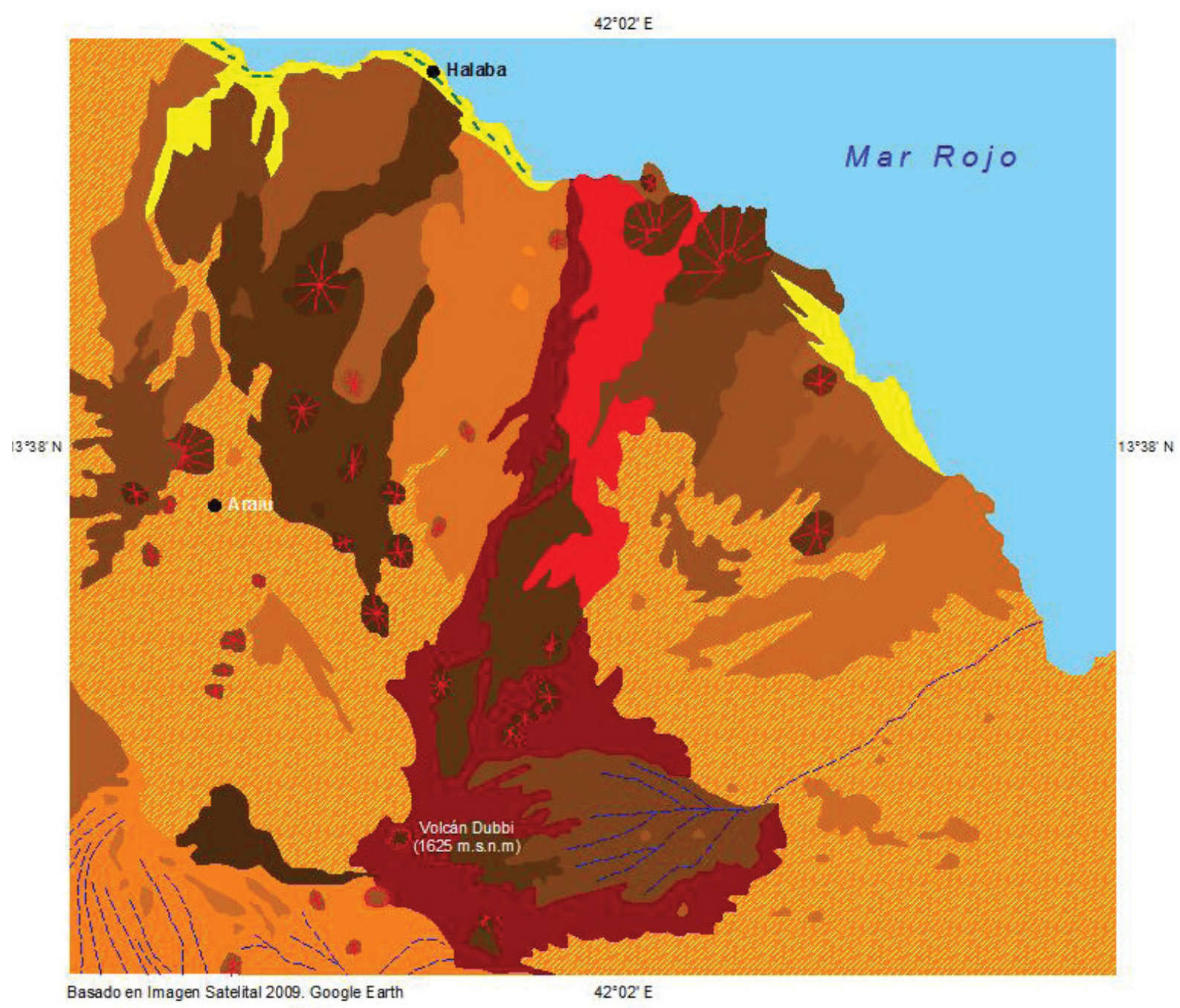

\section{Fotointerpretación: Dr. Jean Pierre Bergoeing}

Cartografia Digital: Bach. Oscar Barrientos Ortiz

Simbologia
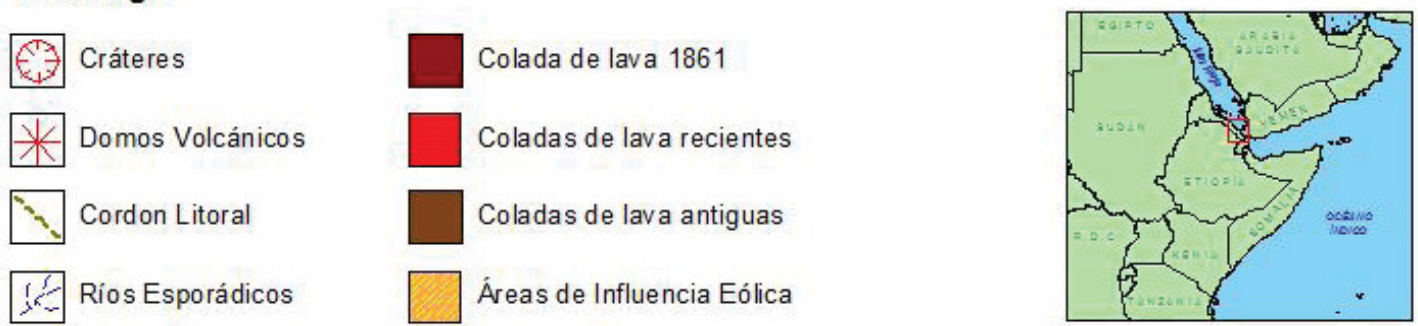

Figura 7 - Volcán activo Dubi, Eritrea ( 1.625 m) Obsérvense las largas coladas de lavas basálicas que han descendido de los diferentes cráteres de este macizo volcánico. (Fotointerpretación basada en imagen Google 2011).

Volcán Nabro

Próximo al volcán Dubi se encuentra el volcán Nabro (Figura 8) que hizo erupción recientemente en junio 2011. Los países más afectados hasta el momento han sido Etiopia, Eritrea, Sudán y Egipto, ubicándose dentro de los países con más cenizas y con vuelos cancelados. La última nube de cenizas llegó a la ciudad de El Cairo. Según los vulcanólogos la primera nube de cenizas incluía particulas pesadas, metales, hidrocarburos y dióxido de azufre, mientras que las última erupción se cree que solo contiene dióxido de azufre, lo que la hace mucho más ligera. El Centro de Observaciones de Cenizas de Toulouse, Francia, no pudo determinar si las nuevas nubes de cenizas tendrian un impacto en los vuelos, sobre todo respecto al dióxido de azufre, pero la extensión de la erupción podrian llegar a afectar has ta Israel. (Figura 8) 
$41^{\circ} 41^{\prime} \mathrm{E}$

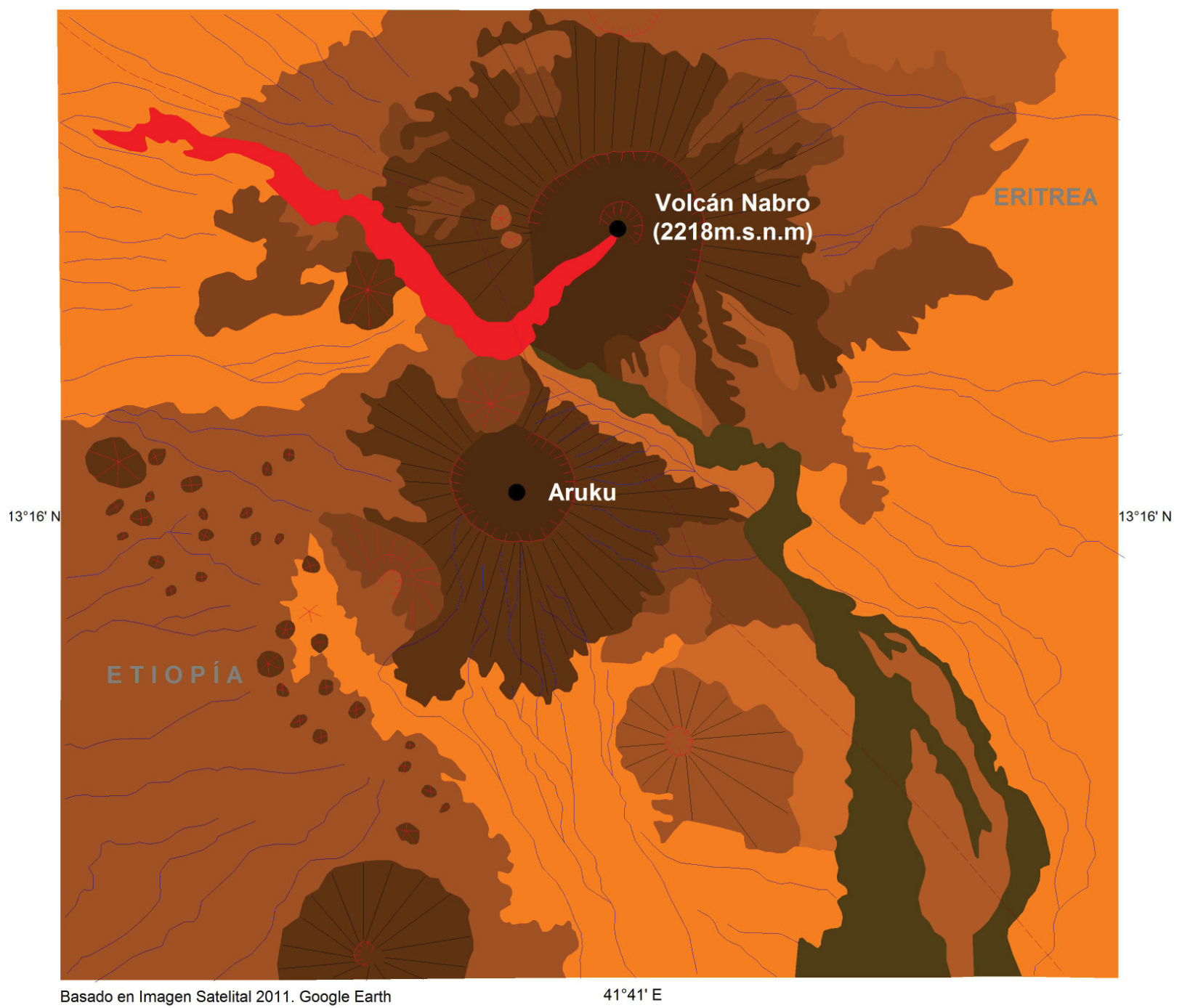

Fotointerpretación: Dr. Jean Pierre Bergoeing

Cartografía Digital: Bach. Oscar Barrientos Ortiz

\section{Simbología}

\begin{tabular}{|c|c|c|}
\hline$\pi+\frac{1}{7}$ & Cráteres & Colada de lava de 12/06/2011 \\
\hline & Domos Volcánicos & Coladas de lava recientes \\
\hline X & Cono Volcánico & Coladas de lava antiguas \\
\hline & Red Hídrica & Límite Internacional \\
\hline
\end{tabular}

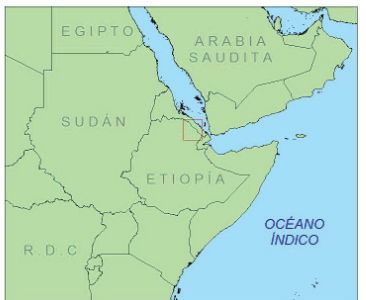

Figura 8 - Caldera del volcán Nabro en la frontera (en amarillo) entre Etiopía y Eritrea. El poblado de Aruku en Etiopía se encuentra construido sobre un segundo cráter Obsérvese la colada basáltica más reciente que fluye hacia el nor-este de la caldera del Nabro. ((Fotointerpretación basada en Imagen satelital Google 2011).

El 12 de junio de 2011 el cráter del Nabro hizo erupción a las 21 horas precedida de fuertes sismos de $5.7^{\circ}$ en la escala de Richter, emitiendo gran cantidad de gases de dioxido de azufre y cenizas que se elevaron a unos $15 \mathrm{~km}$ afectando al Sudán y Egipto, y finalmente una colada incandescente de lava basáltica y riolítica que recorrió varios kilómetros. La erupción hizo siete víctimas en el poblado de Sireru y 31 victimas en el sector Etiope además de cientos de desplazados- El Nabro es un estrato-volcán de la región del Afar en la depresión del Danikil, que alcanza una altitud de 
2.218 metros y se compone de una caldera habierta hacia el sur-oeste, de unos $20 \mathrm{~km}$ de diámetro en cuyo centro se encuentra el cráter activo que hizo erupción y por donde salió una colada de lava muy fluida, principalmente de tipo basáltica que fluyó hacia el nor-oeste recorriendo unos $25 \mathrm{~km}$. También en el sector se encuentra obsidiana en profusión. Fuera de estos conos volcánicos hay una multitud de pequefios domos dacíticos que pululan entre grandes derrames de lavas en particular al norte del poblado de Arukú.

\section{Los Volcanes del Rift Etiope}

\section{Volcán Erta Alé}

En este sector, el punto culminante es el volcán Erta Ale, ( $613 \mathrm{~m}$. de altitud) o "montafía humeante". Es un volcán escudo y uno más de los volcanes de la cordillera oriental del Africa. Situado en Etiopía en las coordenadas $13^{\circ} 42^{\prime}$ lat. N. y $40^{\circ} 67^{\prime}$ long. E. La lava basáltica que sale del volcán Erta Ale es del mismo tipo de la que emerge de los volcanes submarinos. El volcán Erta Alé se caracteriza por tener en su cráter un lago permanente de lava basáltica fundida, donde se forman costras que bajo el empuje de la lava suelen hacer explosiones espectaculares pero de débil amplitud.

La cadena volcánica del Erta Alé es una de los grandes ejes volcánicos del Afar y el que mejor caracteriza a este sector. Se sitúa en el gran Rift, en Etiopia próximo a la frontera con Eritrea entre las coordenadas geográficas $13^{\circ} 36^{\prime}$ de latitud N. y $40^{\circ} 37^{\prime}$ de longitud Este. En lengua Afar, Erta Alé significa montaña humeante. Esta cadena volcánica mide $95 \mathrm{~km}$ de largo y $42 \mathrm{~km}$ de ancho y constituye el sector norte de la depresión del Danakil que baja hasta $-120 \mathrm{~m}$ bajo el nivel del mar, en Etiopia. La cadena volcánica se compone de seis conos; El Erta Alé, el Gada Alé, el Alu-Dala Filla, el Borale Alé, el Hayli Gub, y el Alé Bagu.. La depresión del Danakil marca el limite entre el Rift etíope y las dorsales del Mar Rojo y del golfo de Adén. El Erta Alé se eleva a 635 metros sobre el nivel del mar. El cono tiene pendientes suaves y la base cubre unos $30 \mathrm{~km}$ de diámetro. Es un volcán escudo basáltico. La cumbre está constituida por una caldera de colapso elíptica que mide $1.6 \mathrm{~km}$ de largo por $07 \mathrm{~km}$ de ancho y ocupada por una serie de cráteres que albergan lagos de basalto fundido que pueden extruir en periodos de actividad intensa. Es uno de los únicos volcanes con lago cratérico de lava (desde 1906) junto al Kilauea en Hawai y el Erebus en la Antártida.

Los volcanes de Etiopía son desconocidos en su gran mayoría ya que muy pocos han sido estudiados. Hay 67 volcanes clasificados, de todo tamatio, que van des simples cráteres hasta calderas que se caracterizan por su gran actividad desde géiser y fumarolas hasta erupciones violentas como las del Erta Alé. Todos han tenido actividad reciente (Holoceno). Estos volcanes son el testimonio del inicio del Rift africano, una zona de acreción tectónica que separa la placa Somalí de la placa A fricana creando la depresión del Danakil (Figuras 9, 10, 11, 12 y 13).

La depresión del Afar, que está por debajo del nivel del mar, en Yibuti, en donde se ubica el deprimido lago Abbe ( $-155 \mathrm{~m}$ ) es el lugar donde se está dando la acreción, es decir la separación de la placa tectónica del África con la placa tectónica Somalí. El Mar Rojo ha invadido la depresión del Afar al menos en tres oportunidades en los últimos 200.000 afios, y ello está evidenciado por los estratos salinos en los taludes expuestos de las quebradas. También se le conoce como "triángulo Afar, Danakil, Dancalié". Cubre unos $4.000 \mathrm{~km}^{2}$ y abarca el este de Etiopia, el centro de Eritrea, el sur de Yibuti, y el extremo norte de Somalia. Desde el punto de vista geológico constituye un graben limitado al noreste por el bloque del Danakil en posición de Horst, al oeste y al sur por la meseta etiope que dibuja fallas escalonadas o traps. Al sur la placa Somali se adentra en el sistema dorsal del Yemen. El sector se caracteriza por un sistema de afallamientos normal. 


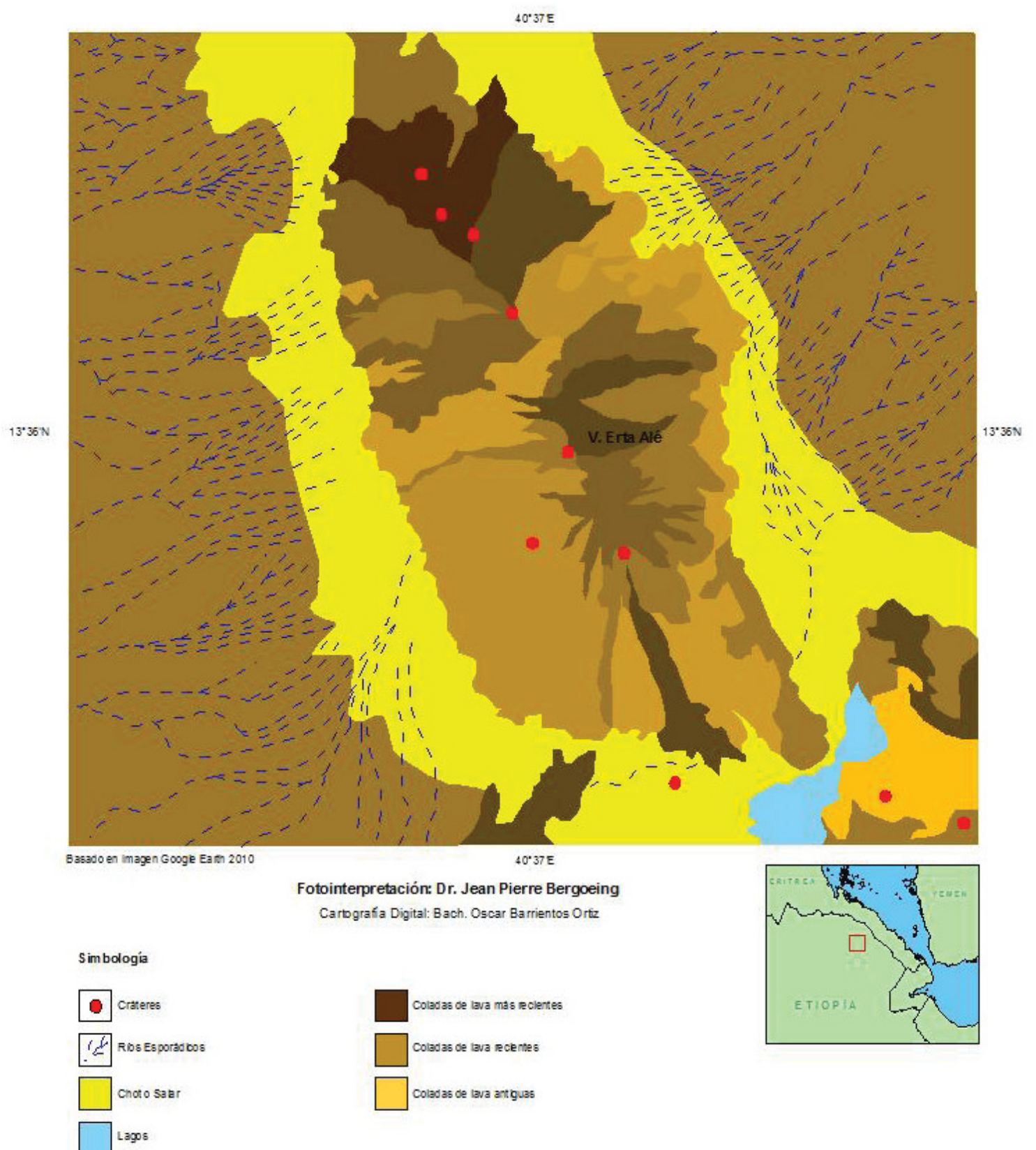

Figura 9 - Cadena volcánica del Erta Alé, situada en la frontera entre Etiopía y Etitrea. Se pueden observar en la. imagen satelital los conos que conforman este macizo volcánico así como las numerosas coladas de lavas basálticas. A los pies del macizo, una geomorfología de paisaje árido compuesta por conos de deyección surcados por cauces secos que terminan en depresiones cerradas ( salares o chots). (Fotointerpretación basada en una imagen satelital Google 2011). 


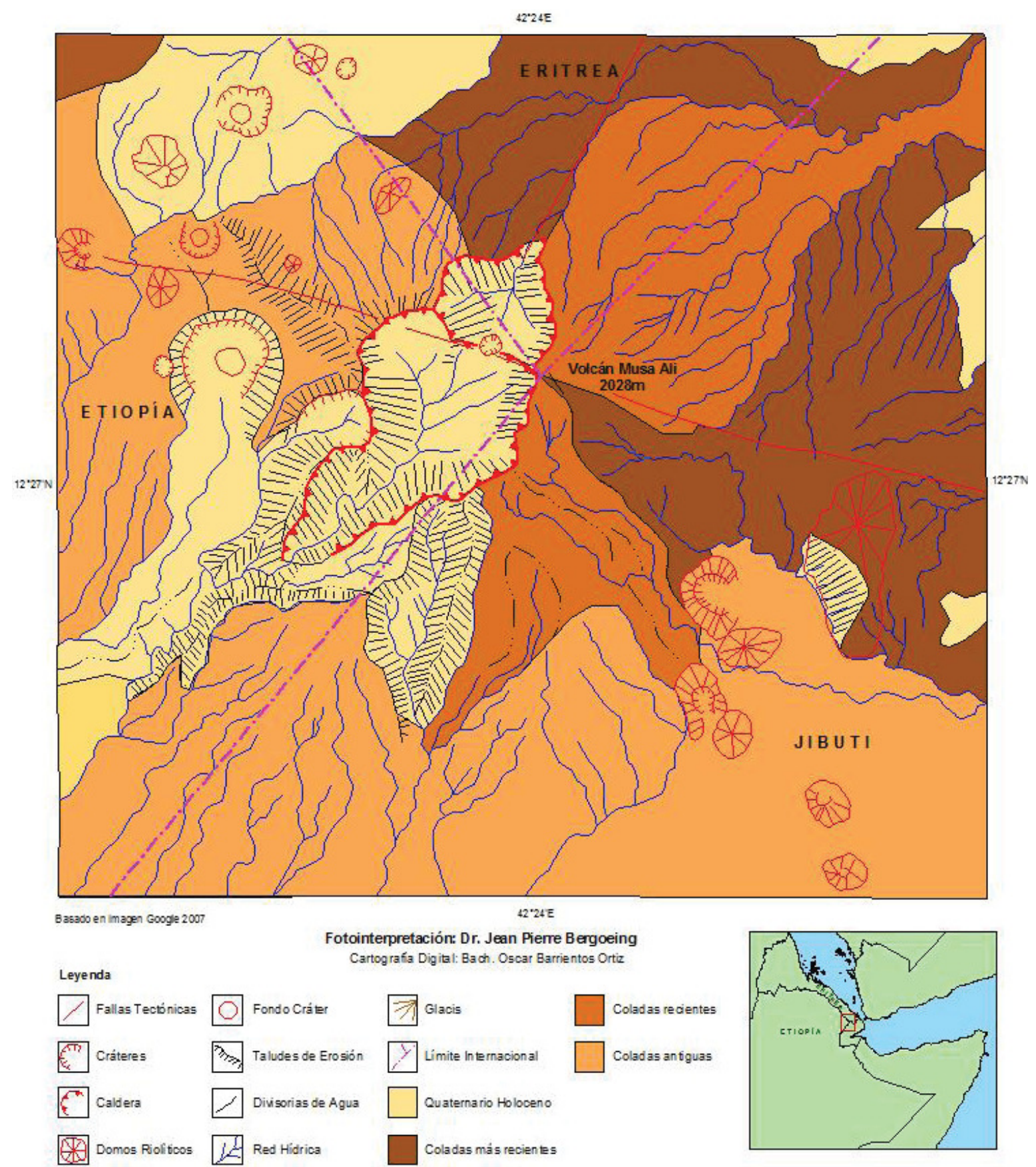

Figura 10 - Volcán Musa Ali. Cumbre de 2.026 m Punto limítrofe entre Eritrea, Etiópia y Jibuti, es una caldera de explosión muy erosionada en clima árido. (Fotointerpretación basada en imagen satelital Google 2007) 


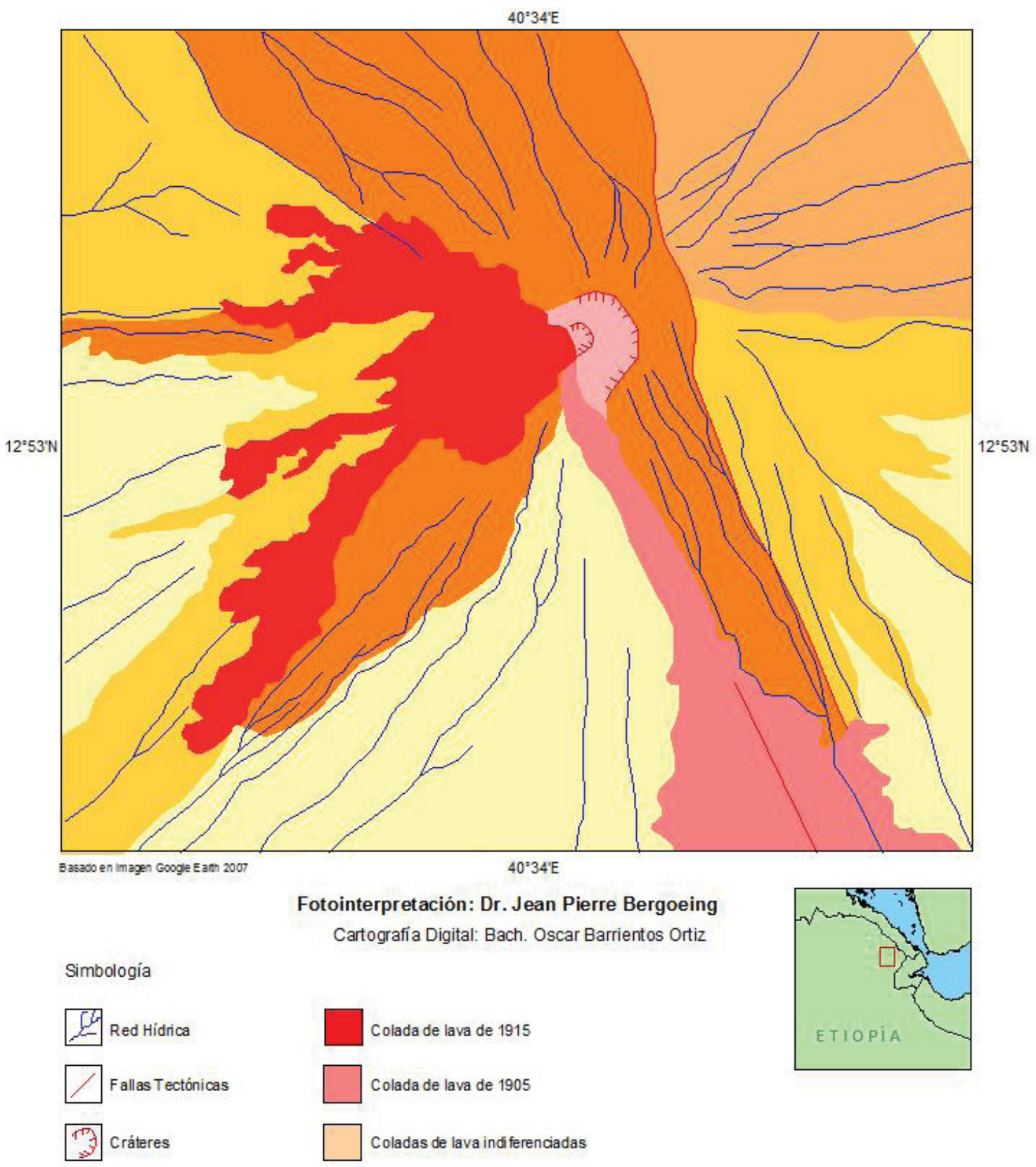

Figura 11 - Volcán Alayta, Etiopía, próximo a la frontera con Eritrea en una de las áreas tectónico-volcánicas más activas del mundo. La colada de lava basáltica de 1915 se derramó hacia el oeste cubriendo gran parte del cono debido a su fluidez. (Fotointerpretación basada en imagen satelital Google 2007.) 


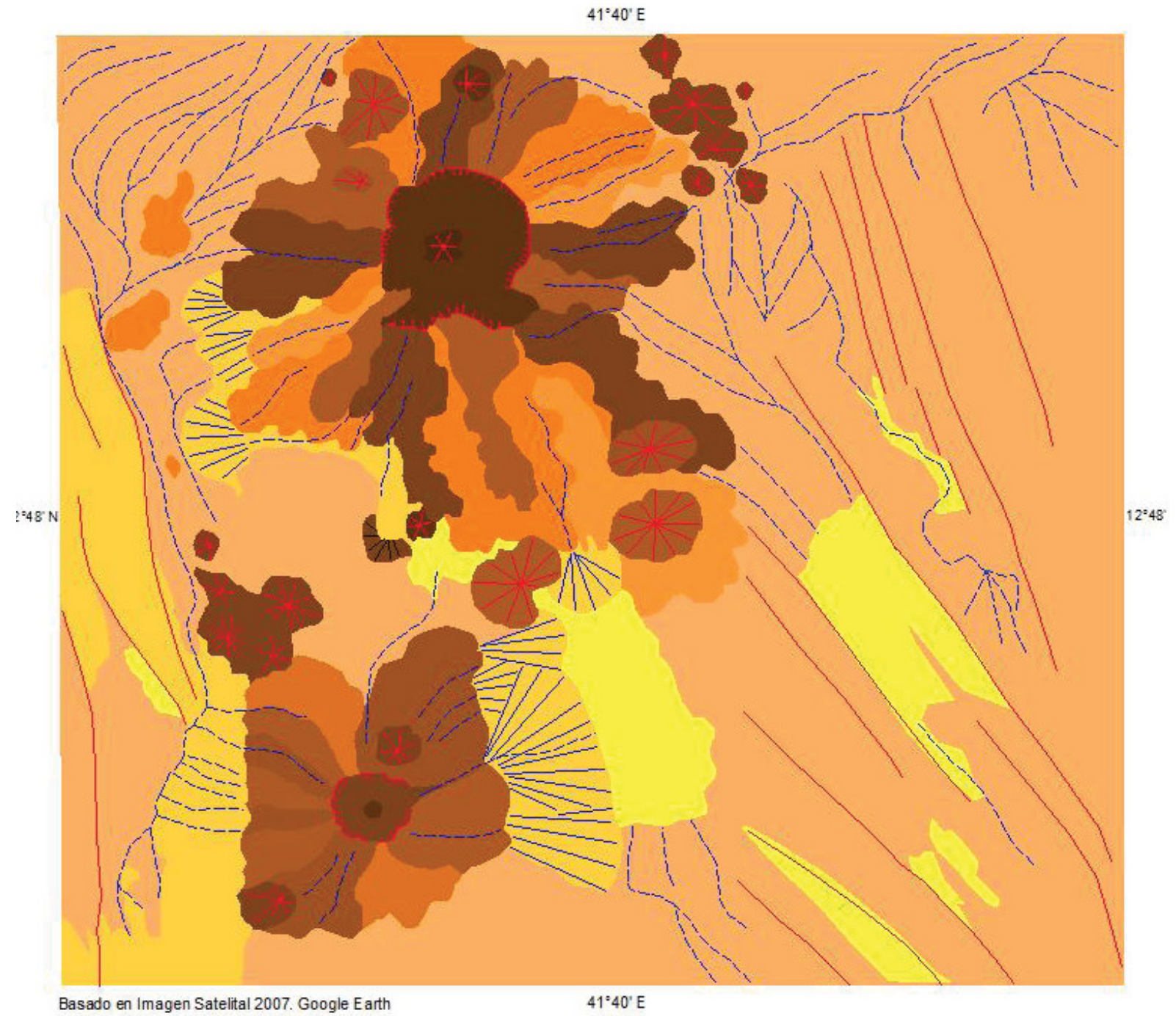

Fotointerpretación: Dr. Jean Pierre Bergoeing

\section{Simbología}

Cartografia Digital: Bach. Oscar Barrientos Ortiz

$\square$ Fallas
\# Domos Volcánicos
Cráteres
Taludes
Gacis
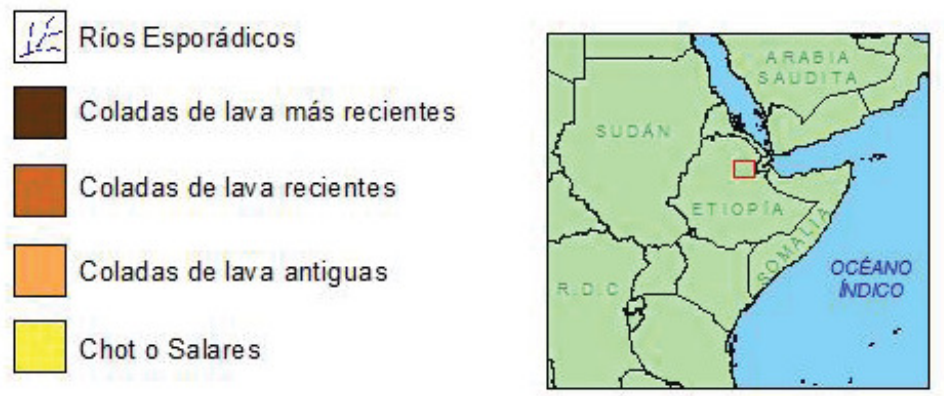

Figura 12 - Antiguas estructuras volcánicas del Danikil. (Fotointerpretación basada en imagen satelital Google 


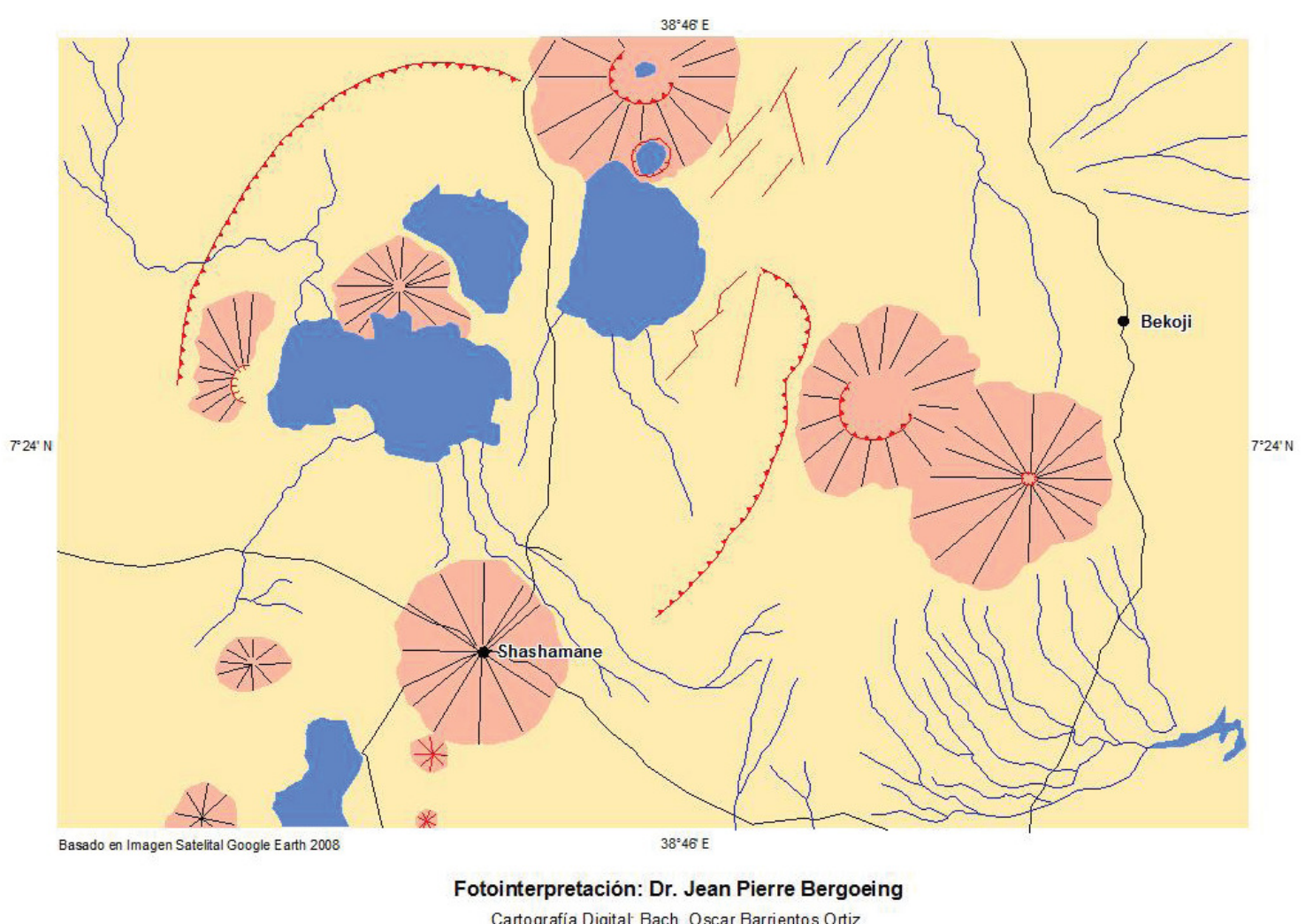

Simbologia
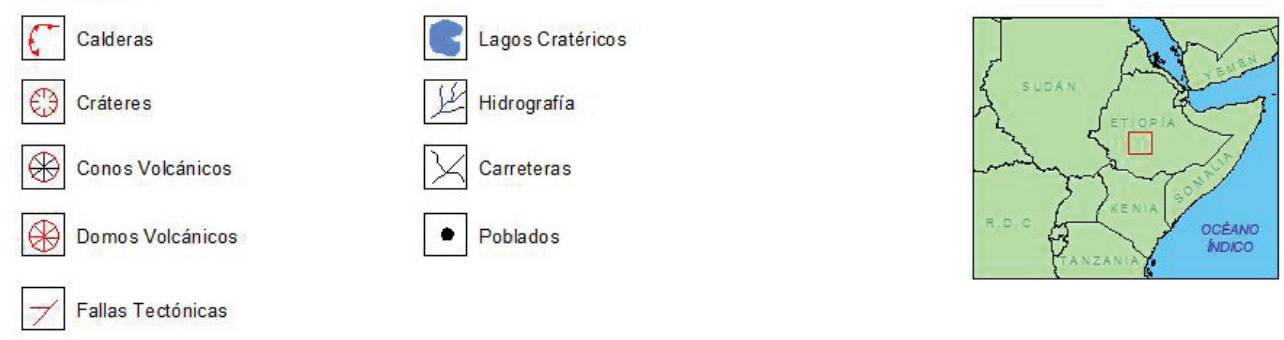

Figura 13 - Lagos cratéricos de Abijata y Langano dentro de una caldera de colapso, en el sur del Rift Etiope, cercanos al poblado de Shashamane. Al este emergen dos domos volcánicos. (Fotointerpretación basada en imagen

\section{EL RIFT ORIENTAL}

\section{Los Volcanes de Kenia y los Grandes Lagos}

El lago Turkana antiguamente conocido como lago Rodolfo, se sitúa al norte de Kenia en la frontera con Etiopia. Se extiende por unos $300 \mathrm{~km}$ y el espejo de agua cubre unos $6.453 \mathrm{~km}^{2}$. Este es el lugar donde el Rift bifurca en dos partes, al este, el lago Turkana dibuja una curva que vendrá a unirse con el Rift oeste enmarcado por los grandes lagos; Alberto Eduardo, Kivu, Tanganika y Nyasa que son la expresión más profunda del desgarre de la corteza terrestre en este sector. 


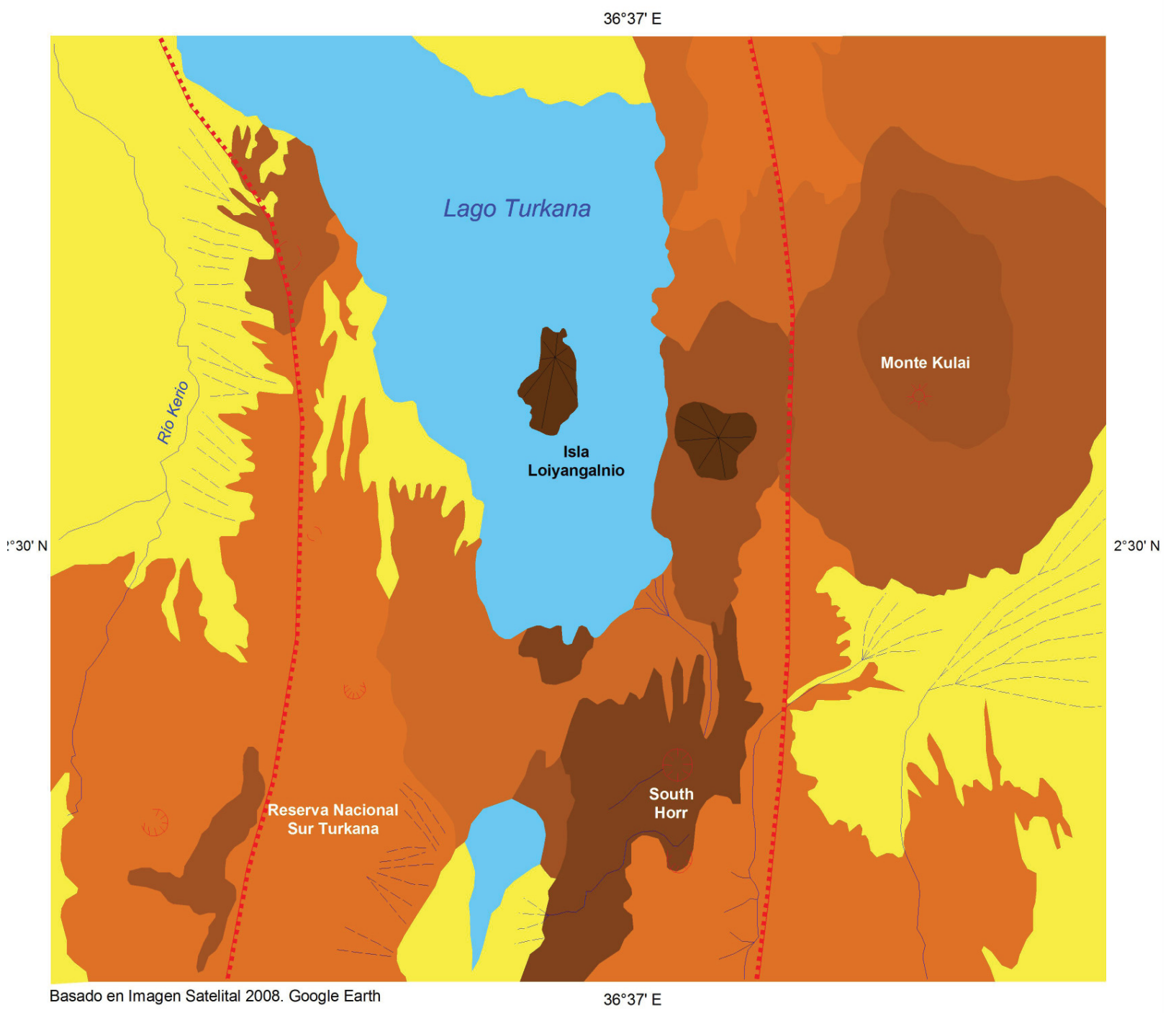

Fotointerpretación: Dr. Jean Pierre Bergoeing

Cartografía Digital: Bach. Oscar Barrientos Ortiz

\section{Simbología}

\begin{tabular}{|c|c|c|}
\hline & Cráteres & Graben \\
\hline & Conos Volcánicos & Coladas de lavas más recientes \\
\hline$\xi$ & Red Hídrica & Coladas de lavas antiguas \\
\hline$\xi$ & Ríos Esporádicos & $\begin{array}{l}\text { Áreas Sedimentarias por } \\
\text { Depósitos Fluviales Esporádicos }\end{array}$ \\
\hline
\end{tabular}
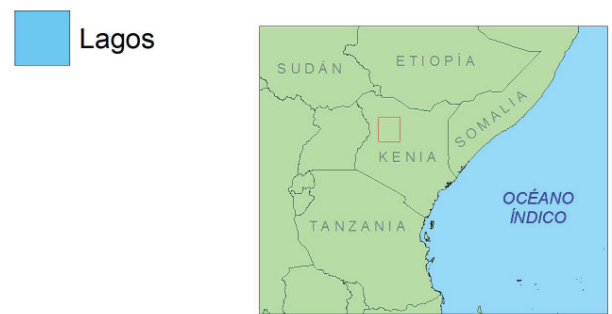

Figura 14 - Sistema voleánico de Kulai, al este del lago Turkana. La isla que conforma et South Island National Park, al centro del lago, es igualmente un cono volcánico emergente. La cima recubierta por una espesa vegetación tropical deja entrever algunas estructuras volcánicas (Cráteres y calderas). A1 sur los Cráteres del Longonot y Suswa. (Fotointerpretación basada en imagen satelital Google 2011). 


\section{El Lago Turkana.}

El lago Turkana, antiguamente lago Rodolfo bautizado en 1888 así en honor del archiduque de Austria Rodolfo de Hasburgo, es un largo endorreico que pierde su nivel por evaporación y se extiende sobre una superficie de $6.405 \mathrm{~km}^{2}$ y está rodeado por un ambiente árido y seco. El lago es de tipo alcalino pero es alimentado por tres rios, el Omo, el Turkwel y el Kerio. Hoy su fauna es solo de peces pero tuvo en el pasado cocodrilos del Nilo.

El sector que bordea el lago Turkana es eminentemente volcánico y aquí emergen, al sur del lago, los conos de los volcanes Longonot y Suswa. El lago Turkana es endorreico y por ello, solo la evaporación solar permite disminuir su masa líquida (Figura 14).

\section{El Volcán Longonot.}

El volcán Longonot se sitúa al sur del lago Turkana, en Kenya entre las coordenadas $0^{\circ} 55^{\prime}$ de lat. Norte y $36^{\circ} 27^{\prime}$ de long.Este (Figura 15). Es un estrato volcán que se eleva a $2776 \mathrm{~m}$. de altitud. Está construido sobre una caldera de $8 \mathrm{~km}$. por $12 \mathrm{~km}$, cuyo fondo es plano y está recubierto por vegetación tropical. Es un volcán de fines del Pleistoceno ya que los geólogos piensan que se formó hace unos 21.000 afios Posee en su centro un cráter de $2 \mathrm{~km}$ de ancho. Las lavas del Longonot son traquíticas y posee al menos dos escurrimientos lávicos laterales fisurales. La caldera del Longonot corresponde a un colapso Holoceno que afectó igualmente el volcán Suswa vecino por lo que se cree que es un fenómeno ligado al drenaje magmático interior del Rift. Según relatos de los autóctonos Masai, el volcán habría hecho erupción en 1863 a partír de un cráter situado en su flanco norte. (http:/www.activolcans.info/volcan-Longonot.html).

\section{El Volcán Suswa.}

El Suswa es un volcán escudo (Figura 16) que se sitúa a $58 \mathrm{~km}$ al este del estrato-volcán Longonot,y a $50 \mathrm{~km}$ de Nairobi la capital de Kenya. Se eleva al sur del lago Turkana y es producto de la ascensión magmática del manto a través del Gran Rift. Aquí el Gran Rift ocupa el sector oriental ya que se desdobla formando un arco. El volcán Suswa se eleva a $2.536 \mathrm{~m}$. de altitud y es un volcán activo cuya última emisión importante cubre todo su flanco este. La cima del volcán está formada por una caldera de $12 \mathrm{~km}$ por $8 \mathrm{~km}$ y en su interior conserva una meseta de lava basáltica muy aplanada. Cerca del rim de la caldera donde el volcán alcanza su mayor altitud, este se caracteriza por poseer un cráter que ha emitido lavas recientes. El volcán se caracteriza igualmente por tener cavemas donde abunda la obsidiana y son el producto de túneles originados por la presión de las lavas que fluyeron al interior mientras los bordes se enfriaban. A los piés del cono volcánico del Suswa, hacia el este, donde se encuentra el poblado de Gicheru, existen derrames de lavas basálticas de tipo fisural que emergieron de una serie de fallas o fisuras tectónicas asociadas al Gran Rift. Aquí es donde toma plena vigencia la hipótesis del colapso de las calderas del Longonot y del Suswa asociadas al drenaje del receptáculo de lavas con aspiraciones del Gran Rift en un momento dado. Igualmente el volcán manifiesta actividad fumarólica en las zonas de fracturas tectono-volcánicas,

\section{El Monte Kenya O Meru.}

El Monte Kenya de $5.199 \mathrm{~m}$ es la segunda cumbre más alta de Kenya y del África detrás del Kilimanjaro. De $5892 \mathrm{~m}$ de altitud. Se sitúa al sur de la línea ecuatorial y es un macizo aislado constituyendo un estrato-volcán inactivo cuya ultima erupción data de fines del Plioceno 2.6 millones de años. En su cima existen pequefios remanentes de un gran glaciar que fue activo durante el último periodo glaciar. Es un volcán complejo, cuyo flanco este colapsó formando hace 7.800 afios una caldera en semi-círculo. Está constituido principalmente por depósitos volcánicos piroclásticos de brechas y tobas y por lavas nefelínicas y fonoliticas. Su actividad comenzó a inicios del Cuaternario hace 2 M.a. según muestras datadas y se prosiguió hasta 1.5 M.a. , Luego vino una fase de reposo y 


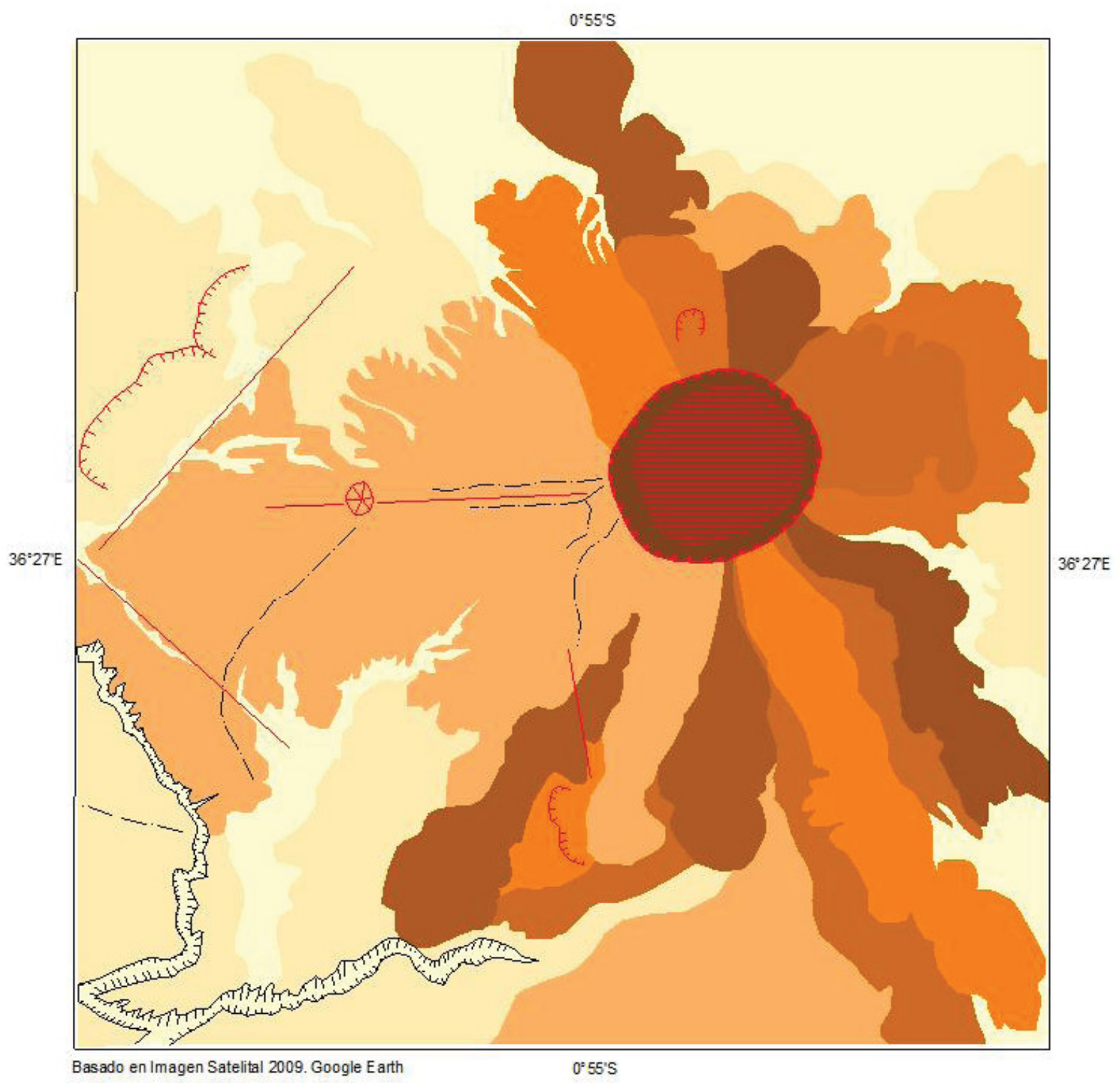

Fotointerpretación: Dr. Jean Pierre Bergoeing

Cartografía Digital: Bach. Oscar Barrientos Ortiz

\section{Leyenda}

$\nearrow$ Fallas Tectónicas

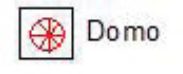

6 Caldera

Escarpes

Fondo Caldera

Líneas de Cresta

Cráteres

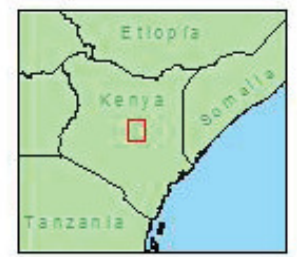

Figura 15 - Cono y cráter del voleán Longonot. Obsérvese las numerosas coladas fluidas que componen su cono y en particular las oscuras que son las más recientes. (Fotointerpretación basada en imagen satelital Google 2011). 

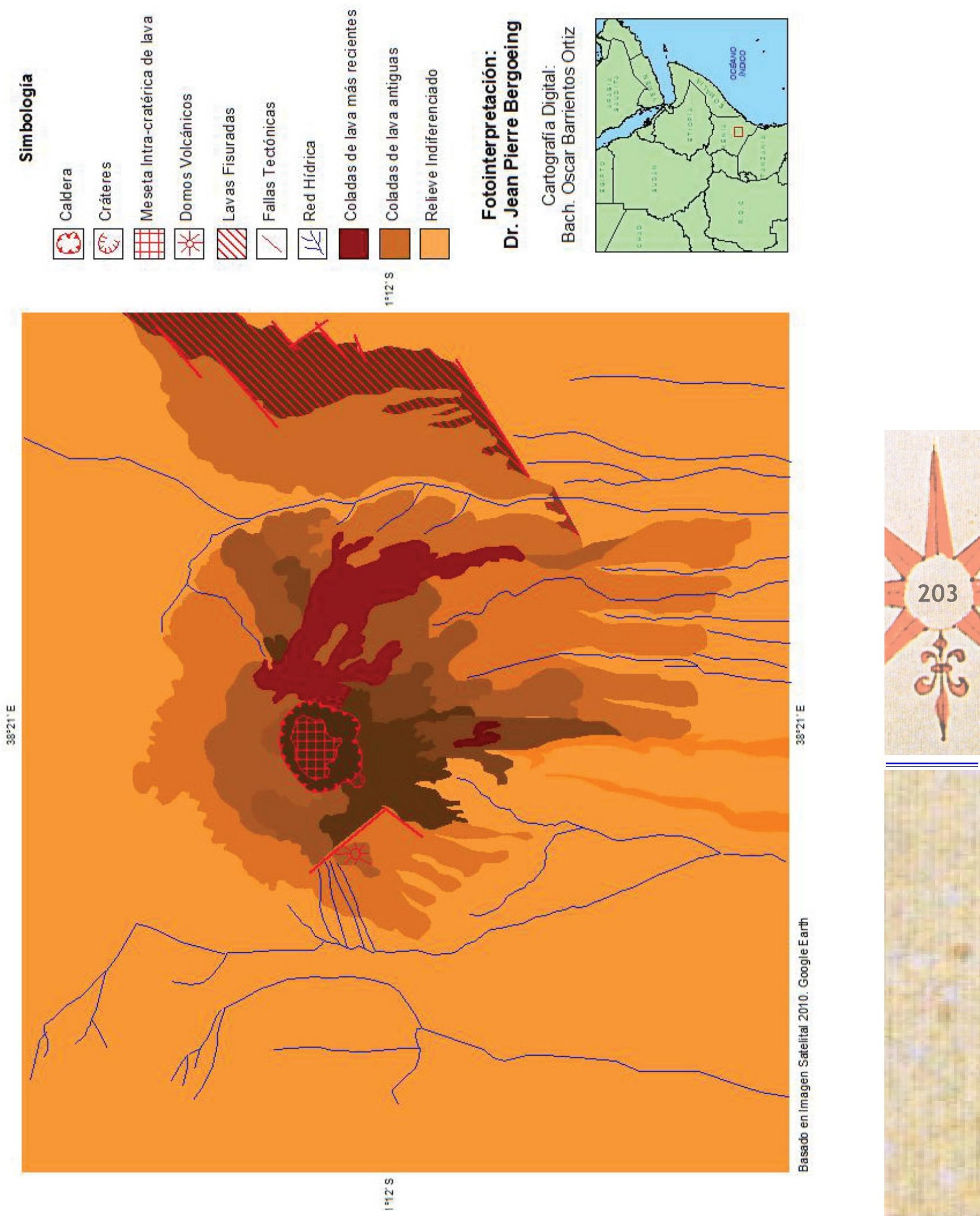

Fig.ura 16 - Volcán Suswa asociado al colapso de la caldera del Longonot. (Fotointerpretación basada en imagen satelital Google 2011.) 
un reinicio de la actividad hace $0.16 \mathrm{M}$ a ( fines del Pleistoceno superior) ininterrumpida. El cono principal se edificó entre 0.16 M.a. y 0.06 M.a. (Holoceno). Durante este último periodo se construyó el Ash Cone o cono de cenizas formado por piroclastos nefelínicos y que continúa en actividad.

A los piés del monte Meru, al este emerge el cráter del Ngurdoto y al oeste el Monduli que es un complejo basáltico datado de 1.67 M.a. El sector aldeafio está sembrado de conos parásitos estrombólicos que constituyen la meseta de Arusha-Mondoli (NONNOTTE Ph. 2007.)

\section{El Kilimanjaro.}

Tal vez el volcán más emblemático de África, por albergar nieves eternas en su cumbre lo cual dejó pasmados a los primeros exploradores europeos, en el siglo XIX, que no podían creer ver nieve a latitudes ecuatoriales. Descubierto por Johannes Rebmann en 1848 , se sitúa al noreste de Tanzania y se compone por tres cráteres, el Shira al oeste que alcanza $3.962 \mathrm{~m}$, el Mawenzi al este que se eleva a $5.149 \mathrm{~m}$ y el Kibo que es el más joven estructuralmente hablando. El punto culminante se encuentra en el pico Uhuru, que es la cima del Kilimanjaro y que se eleva a 5.891 .8 metros de altitud y es el punto más elevado de África.

El Kilimanjaro es un estrato volcán del Cuatemario (Figura 17), expresión de las subidas magmáticas del manto a través de la corteza terrestre en esta zona de debilidad que es el graben del Gran Rift. Se calcula que la edificación del Kilimanjaro comenzó con el cono del Shira hace 750.000 afios, seguido por el colapso del mismo que formó una caldera. Posteriormente se edificó el Mawenzi seguido del Kibo. Las lavas viscosas del Kibo colmataron la caldera del Shira, constituyendo una meseta volcánica. La última erupción del Kibo se remonta a 360.000 años. La altitud alcanzada por este macizo volcánico le ha permitido albergar un casquete glaciar contemporáneo con las ultimas glaciaciones lo que ha dejado trazas de valles en $U$ y morrenas. El cono volcánico del Shira $(3.962 \mathrm{~m}$.) es un centro de emisión de lavas máficas con gran acumulación de piroclastos y tobas basálticas. El Mawenzi ( $5.249 \mathrm{~m}$.) localizado en el este es una estructura densa formada por diques máficos y brechas pirocláticas. Al centro el cono Kibo representa el edificio central que alcanza los 5.895 m en el Pico Uhuru. Se presenta como una torre cuya cima tiene la forma de una silla de montar. Su actividad volcánica ha sido intensa y está rodeado por conos parásitos de tipo tobas estrombolianas a traquibasálticas. Las laderas del Kilimanjjaro igualmente han tenido actividad eruptiva efusiva con lavas heterogéneas que van de las fonolitas afiricas a las fonolitas téfricas (Ph. Nonnotte, 2007).

\section{VOLCANES AL SUR DEL LAGO NATRÓN, TANZANIA}

Los volcanes al sur del lago Natrón en Tanzania fueron estudiados Philippe Nonnotte (Nonnotte, 2007) quien hizo su tésis de Doctorado en la Universidad de Bretaña occidental, Francia. Aquí emergen conos como el $\mathrm{Ol}$ Doinyo Longai, el Kerimasi, el volcán Olmoti que alcanza los $3.099 \mathrm{~m}$ y posee un lago pluvial al interior de su cráter, $y$ la gran caldera del Ngorongoro. Al este emergen los conos aislados del volcán gelai y del Ketumbeine.

\section{El Volcán Ol Doinyo Lengai}

Se localiza en Tanzania por las coordenadas $2^{\circ} 75^{\prime}$ lat. S. y $35^{\circ}$ long. E. Localmente es mejor conocido bajo el nombre de Ol Doinyo Lengai y alcanza $\operatorname{los} 2.890 \mathrm{~m}$. de altitud. Entró en erupción el 13 de marzo de 2008 lanzando columnas de cenizas de $10 \mathrm{~km}$ de altitud y flujos piroclásticos. El 6 de septiembre de 2008 el volcán emitió coladas fluidas basálticas

El Lengai es un pequefio cono volcánico comparado con los gigantes que se erigen más al sur en lo que podemos llamar la sierra del Ngorongoro (Figura 18).

Las cuencas del lago Natrón y del lago Engaruka se caracterizan por la presencia de cuatro edificios volcánicos principales. Al suroeste del lago Natrón emergen los conos de los volcanes; 


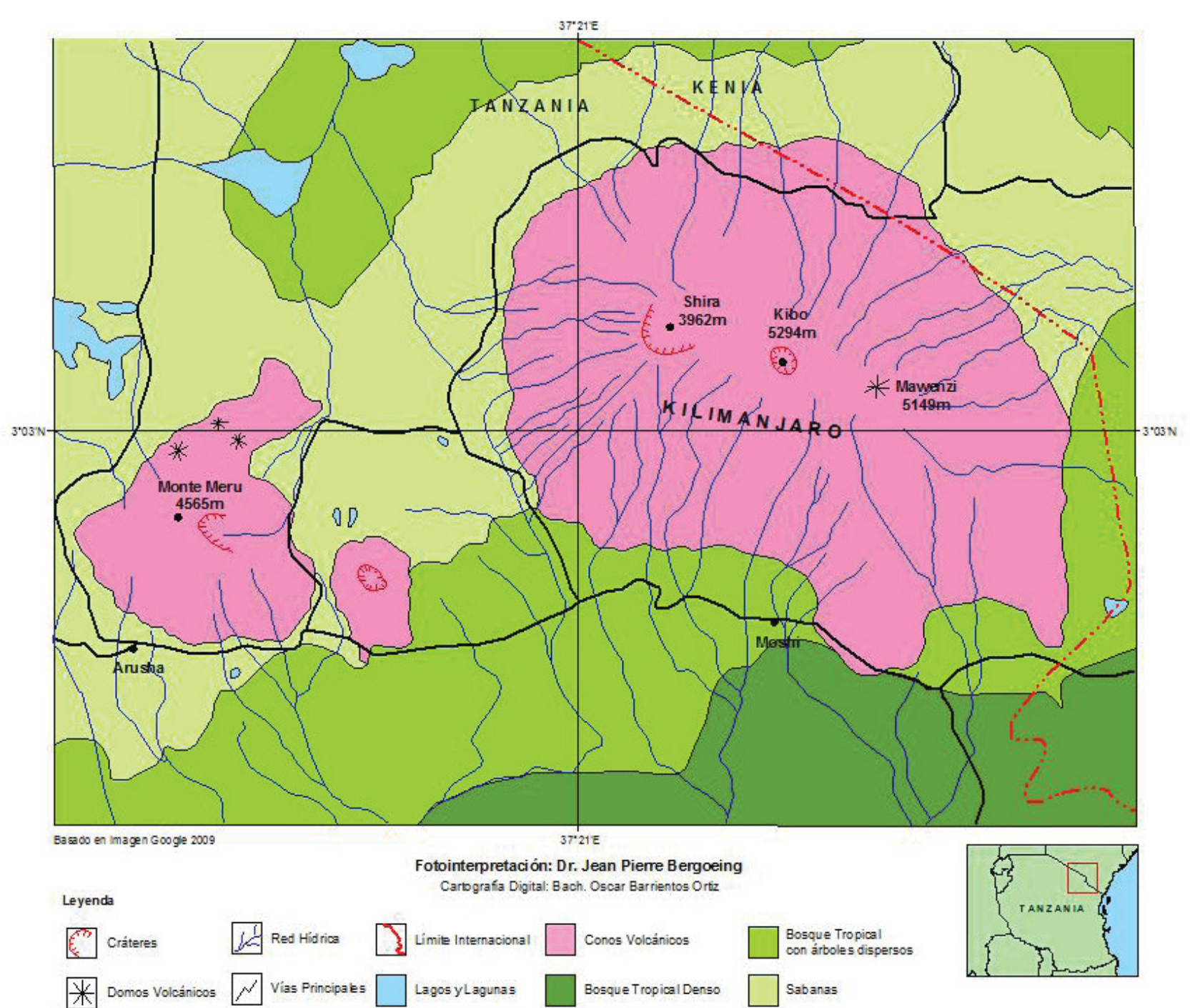

Figura 17 - Voleán Kilimanjaro y Monte Meru. Basado en una fotointerpretación de imagen satelital Google 2010.

Kerimasi, este último activo hasta $0.32 \mathrm{M}$ a y del Ol Doinyo Lengai cuya primera erupción data de 0.17 M.a y continúa en actividad hasta hoy. Es el único volcán carbonatítico del mundo. Son dos volcanes muy parecidos por estar constituidos por formaciones brechosas nefeliniticas a fonolíticas.

El borde suroriental del lago Natrón está constituido por dos grandes volcanes que culminan a $3.000 \mathrm{~m}$. de altitud como lo son el volcán Gelai y el volcán Ketumbeine formados por lavas basálticas y basaníticas. Las dataciones del Ketumbeine dan una edad de 1.87 a 1.54 M.a (Pleistoceno inferior). La edad del volcán Gelai es más joven y da 096 M.a. (Pleistoceno medio).

\section{Volcan Olmoti.}

Este volcán se sitúa entre el Empaki al sur y el Loolmalasin al Noreste. Descansa sobre una meseta que se eleva a $2.600 \mathrm{~m}$. de altitud. Su cráter es en realidad una caldera de $10 \mathrm{~km}$ de diámetro y se caracteriza por depósitos de tobas y ha sido datado de 1.65 M.a. a 1.07 M.a. lo que lo sitúa en el Pleistoceno inferior. Ha emitido lavas de tipo traquiandesiticas, traquiticas y tefrifonoliticas asi como piroclastos ignimbríticos datados de $1.25 \mathrm{Ma}$.

La actividad volcánica más antigua del área se remonta a 8.1 M.a.(Mioceno superior) que incluye los edificios volcánicos meridionales de Essimingor, Burko y Tarosero. Actualmente el único 

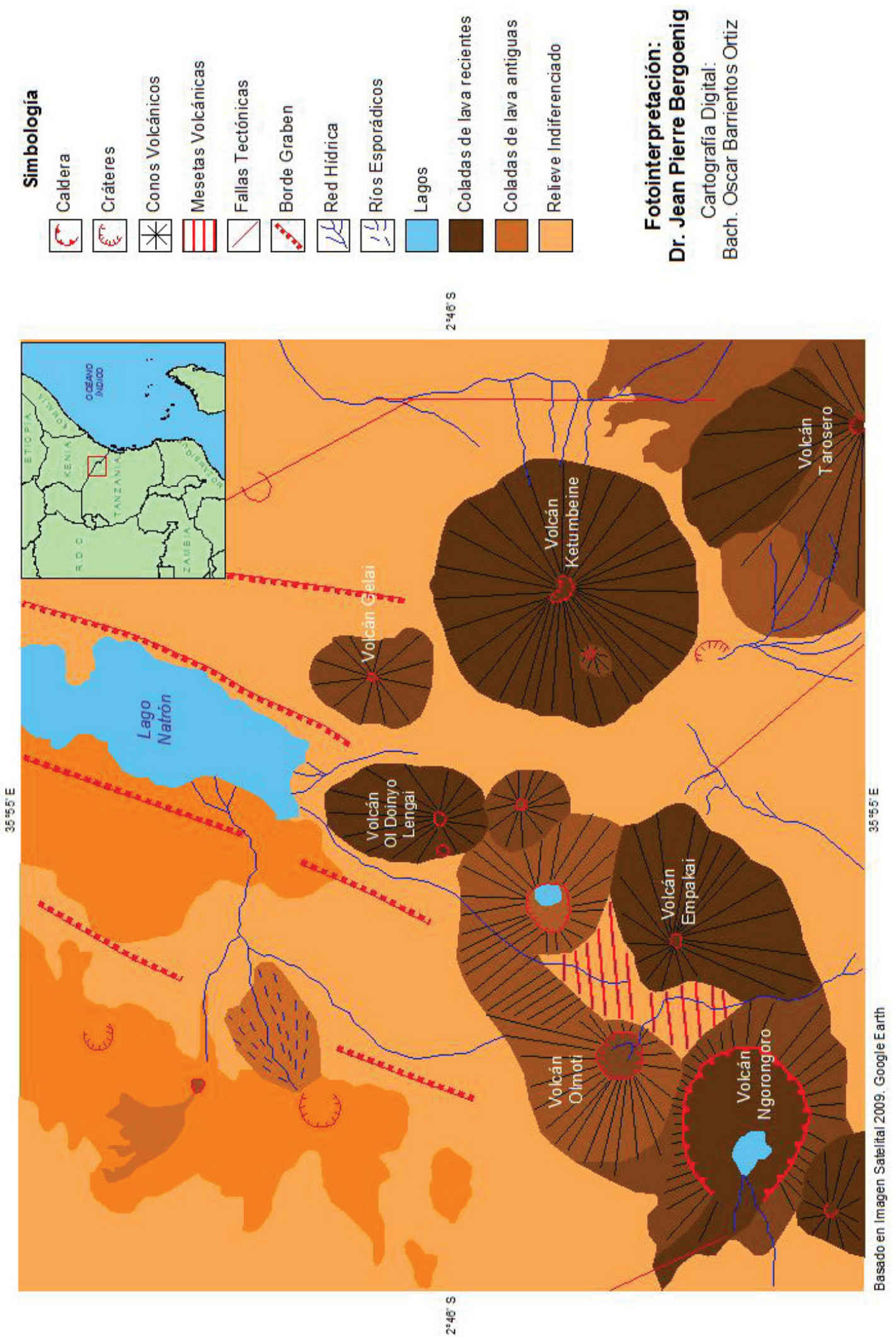

Figura 18 - Sector voleánico sur del lago Natrón, Tanzania. A1 sur en línea, los voleanes O1 Doyno Lengai, Kerima Empakai, Olmoti y la gran caldera del Ngorongor. A1 Este los conos aislados del volcán Gelai y del Ketumbeine, 
volcán activo del sector es el Ol Doyno Lengai Los lagos Natrón y más al sur Mayara constituyen el valle axial del Rift, constituido por un sistema de grabens que tienen desniveles que van de los $1.000 \mathrm{~m}$. a $\operatorname{los} 3.000 \mathrm{~m}$.

\section{Volcan Ngorongoro.}

Más al sur emerge la caldera inmensa del volcán Ngorongoro cuyas dimensiones son $23 \mathrm{~km}$ de diámetro y cubre una superficie de $260 \mathrm{~km}^{2}$. y su rim caldérico alcanza una altitud de $2.453 \mathrm{~m}$ con unos $300 \mathrm{~m}$. de desnivel sobre le fondo de la caldera. Es un volcán datado de $3.7 \mathrm{Ma}$ (Plioceno) a 1.88 M.a. Cuaternario antiguo y que ha tenido un pasado muy explosivo cuyos depósitos se componen de lavas traquíticas, depósitos piroclasticos ignimbríticos y gran acumulación de cenizas que hoy tapizan la meseta del Serengeti. El Ngorongoro habria tenido su última actividad hacia 1.16 M.a. (Pleistoceno medio). En efecto la caldera del Ngorongoro colapsó en varias etapas entrecortadas por erupciones de coladas de lavas. Al final del colapso persistió una débil activ idad volcánica manifestada en el fondo del crátert por emisiones de lavas basálticas y formación de pequeños conos estrombolianos formados por escorias y que se remontarian a 1.16 M.a ( Ph. Nonnotte, 2007).

\section{EL RIFT OCCIDENTAL}

El Rift Occidental o Rift Albertino abarca el sector que comprende la extremidad norte del lago Alberto hasta el sur del lago Kivu, donde se ha trazado la frontera entre Uganda, la República Democrática del Congo, Ruanda, Burundi y Tanzania. En este sector, encontramos diferentes modalidades de actividad volcánica producto de la ascensión magmática a través de las fisuras del Gran Rift occidental. Aquí se destaca el Monte Ruwenzori con más de $5.000 \mathrm{~m}$. y que posee glaciares en su cima.

\section{El Campo Volcanico de Kichwambe.}

El sector es conocido como campo volcánico de Kichwambe que se sitúa al sur del lago Jorge (Figura 19). Se caracteriza por maares o cráteres de explosión gaseosa que están datados de fines del Pleistoceno comienzos del Holoceno y probablemente su actividad se prolongó hasta tiempos his tóricos. Está compuesto por más de 130 maares ocupados por lagunas, de las cuales algunas son salobres. Los maares son cráteres producto de explosiones entre una napa freática o un río subterráneo y un ascenso magmático lo cual produce formación de enormes cantidades de gas que ascienden explotando en la superficie y creando un cráter que será luego alimentado por la napa freática. Se encuentran en este sector igualmente lavas que componen el subsuelo y que son de tipo diorítico-foiditico.

\section{La Cordillera Volcanica del Virunga}

En la frontera entre Uganda, Ruanda y la República Democrática del Congo se eleva una cadena montafíosa volcánica, conocida como Cordillera del Virunga (Figura 20), compuesta por ocho macizos volcánicos donde se destaca el Karsimbi de $4.507 \mathrm{~m}$ de altitud que es la mayor elevación de este complejo, le siguen el Muhavura (4.127 m.), el Gahinga (3.474 m.), el Visoke (3.711 m), el Munavura, el Niamuragira. El volcán más antiguo es el Sabinyo que se eleva a $3.634 \mathrm{~m}$. y finalmente el Nyiragongo que presenta gran actividad volcánica. Esta cadena volcánica es de reciente formación (Holoceno) que es un testimonio de la gran actividad tectónica del Rift occidental en este sector.

\section{El Volcán Karisimbi}

El Karisimbi un estrato-volcán basanítico-traquítico llega a los $4.507 \mathrm{~m}$. de altitud y posee una caldera de $2 \mathrm{~km}$ de diámetro, la "caldera blanca" que es el testigo de un cono mellizo y además 


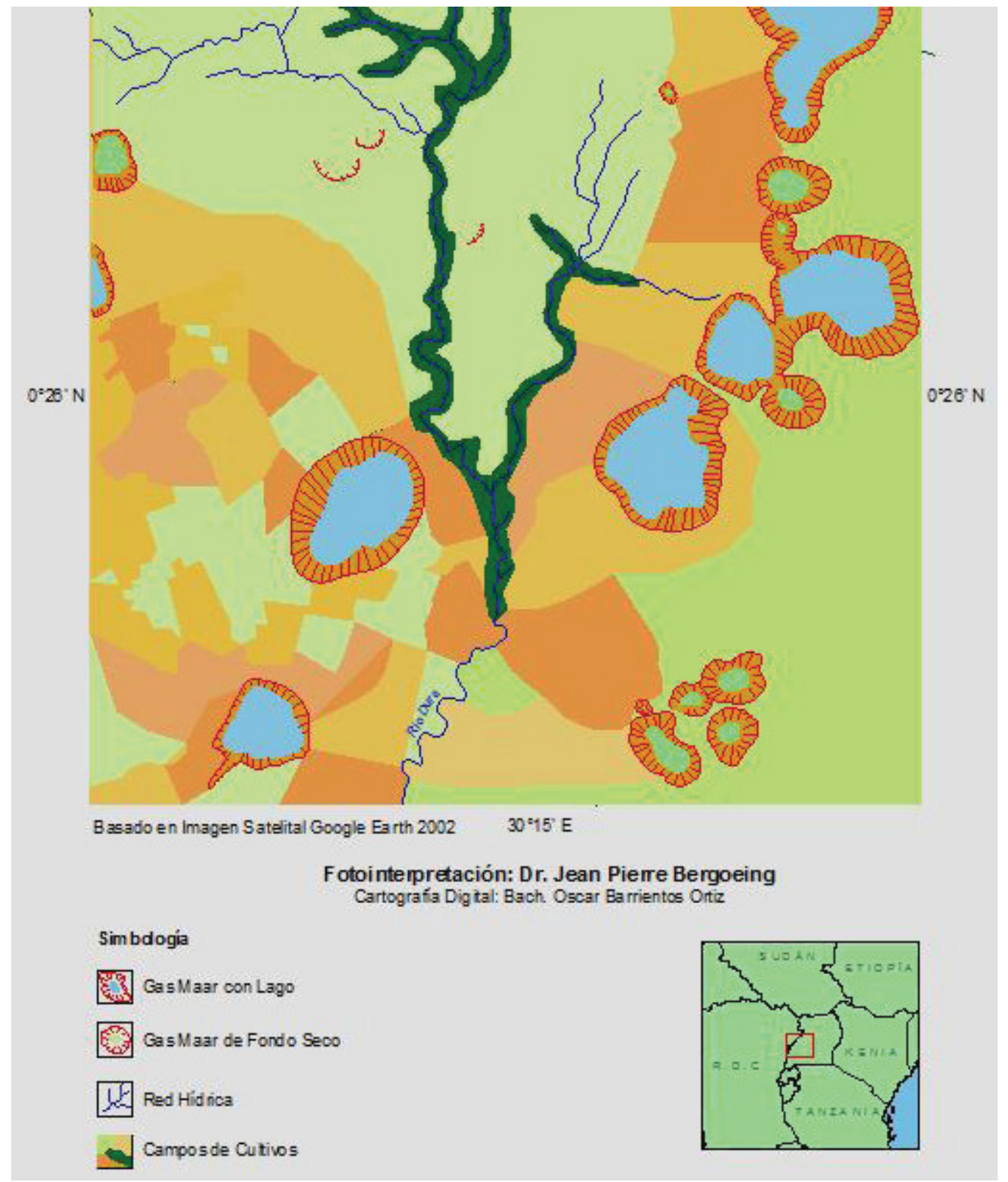

Figura 19 - Sucesión de gasmaares del campo volcánico de Kichwambe, Uganda. (Fotointerpretación basada en imagen satelital Google 2002.) 


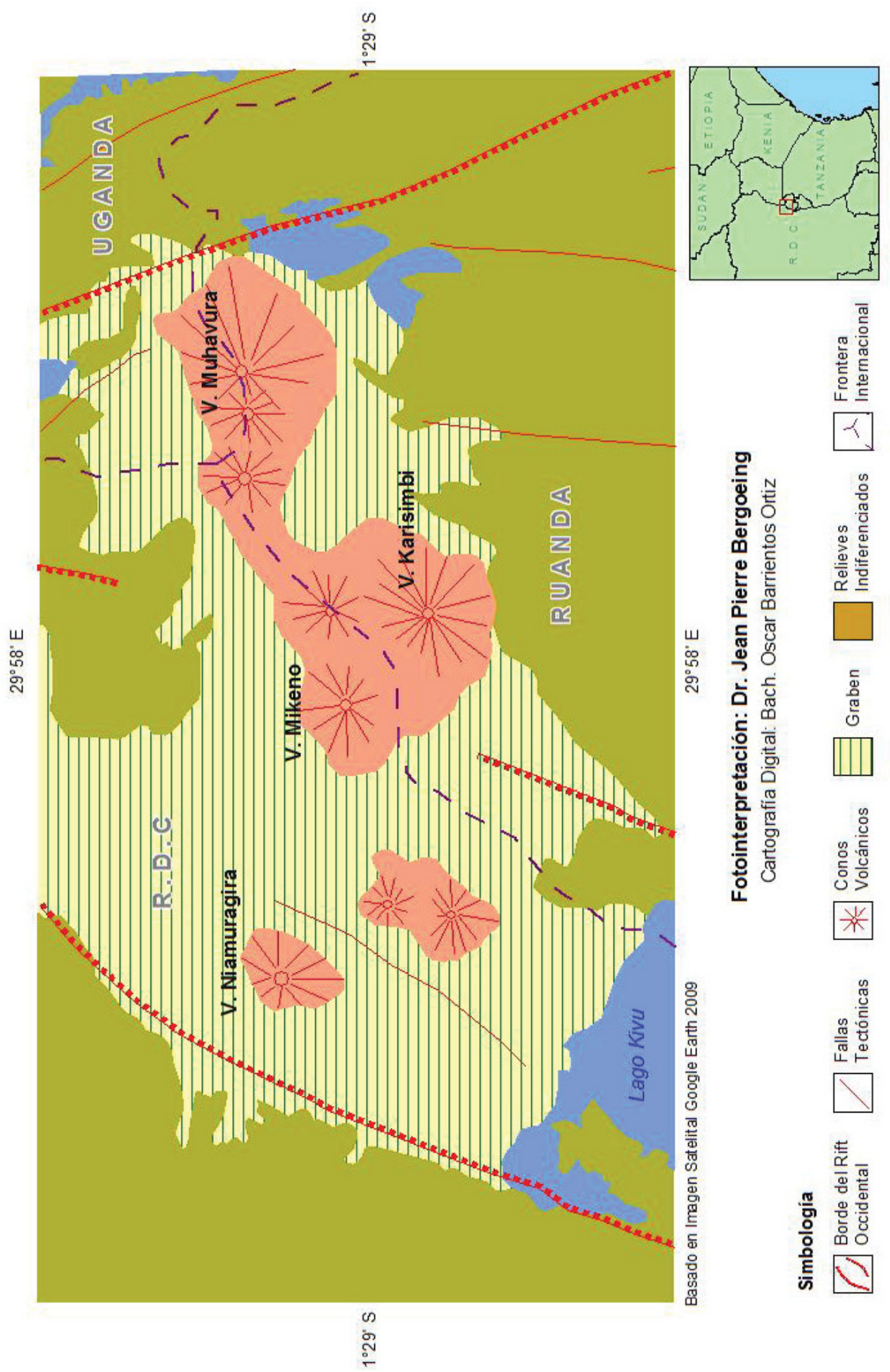

Figura 20 - Cordillera volénica del Virunga compartida por la Republica Democrática del Congo, Ruanda y Uganda. (Fotointerpretación basada en imagen satelital Google 2009.) 


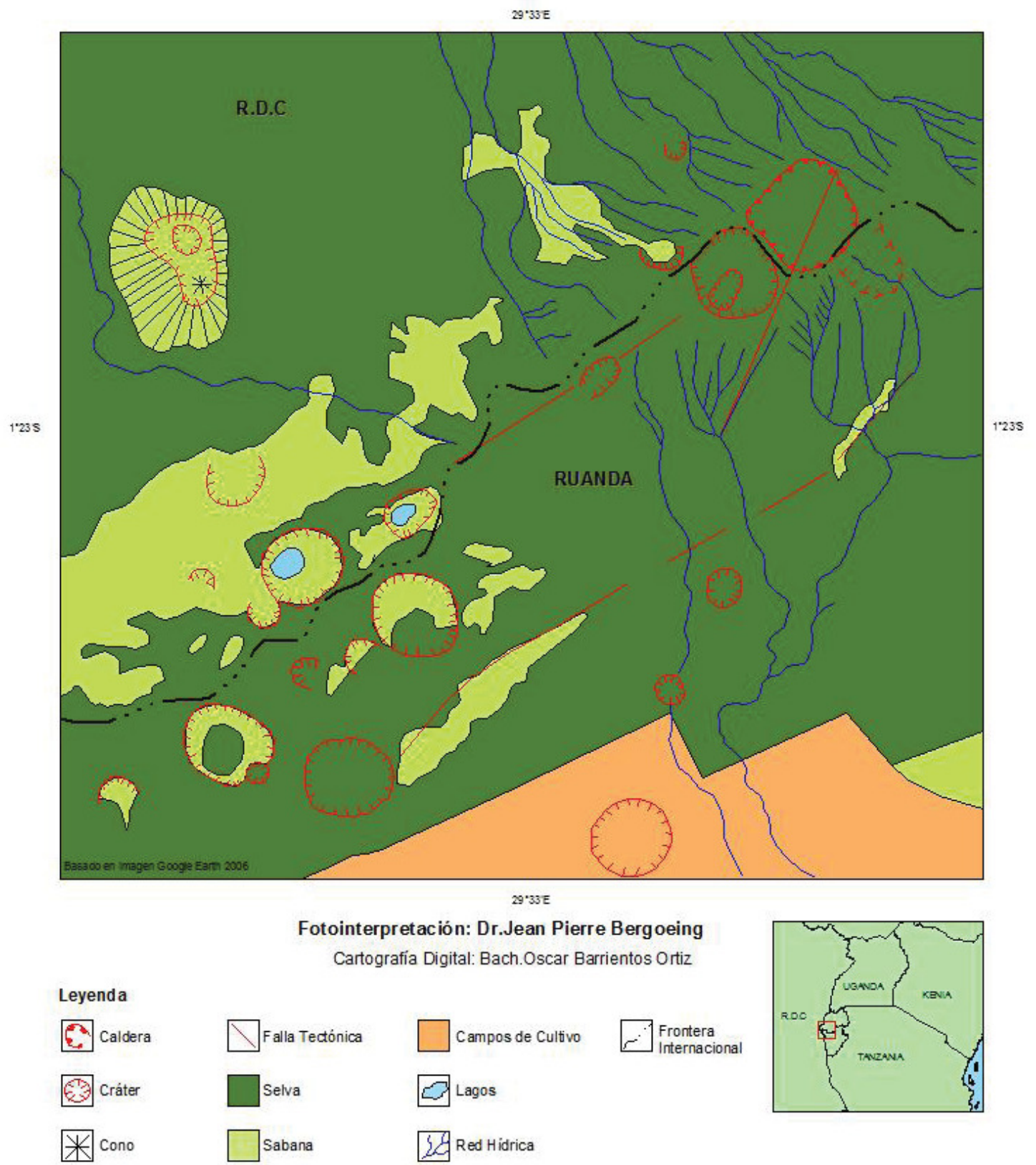

Figura 21 - Voleán Sabinio (3.643 m.) Cordillera del Virunga. ((Fotointerpretación basada en imagen satelital Google 2006). 
un cono parásito cercano de su cima, el Mutanjo, que conformant un macizo volcánico Ha hecho erupción recientemente en 1977 y en 2002.

\section{El Volcan Niamuragira}

El Niamuragira es uno de los volcanes más activos de Äfrica. Es un volcán-escudo basáltico que se sitúa al norte del lago Kivu y contrasta con su vecino el Nyiragongo de $3.470 \mathrm{~m}$ de al titud. Ha emitido grandes coladas de lavas basálticas. Su cima está ocupada por una caldera de $2 \mathrm{~km}$ de diámetro con un rim de 100 metros de desnivel y el cono presenta numerosos conos cineríticos. Hasta 1938 poseyó un lago de lava que fue drenado por una erupción lateral catas trófica que recorrió $30 \mathrm{~km}$ antes de alcanzar el lago Kivu.

\section{El Volcan Muhavura}

El Muhavura se sitúa al Nor-este, al final de la cordillera del Virunga y alcanza los 4.127 de altitud, es un estrato-volcán que alberga un lago pluvial en su cráter. El edificio está compartido por el cono del Gahinga que alcanza $\operatorname{los} 3.473 \mathrm{~m}$. Ambos volcanes han emitido lavas traquitico-andesíticas.

\section{Volcan Sabinyo}

El Sabinyo o Sabinio es un volcán inactivo de la Cordillera del Virunga (Figura21) que alcanza $\operatorname{los} 3.634 \mathrm{~m}$ de altitud. Su cumbre marca la frontera entre la República Democrática del Congo, y Ruanda. Es el habitat del gorila de montafia.

\section{El Volcan Visoke}

El Visoke es un estrato-volcán traquitico-andesítico que se ubica en el extremo meridional de la cordillera volcánica del Virunga. Alcanza los 3.711 metros de altitud y su cráter posee una laguna pluvial. Está rodeado igualmente por conos parasitos de los cuales dos se destacan en su flanco norte.

\section{El Volcán Nyiragongo (3.470 M)}

El Nyiragongo con coordenadas $1^{\circ} 31^{\prime} 07^{\prime \prime}$ sw lat. S. y $29^{\circ} 15^{\prime} 14^{\prime \prime}$ de long. E. es un estrato-volcán situado en la serranía del Virunga, (hogar de los gorilas de montaña) entre la República Democrática del Congo y Ruanda. Es una de las manifestaciones más espectaculares del graben del Rift. Domina desde sus $3.470 \mathrm{~m}$. la ciudad de Goma y el lago Kivu. Tiene erupciones frecuentes y suele derramar potentes coladas de lava basáltica que se escurren con gran velocidad por sus laderas. En su interior, el cráter alberga un lago de lava en fusión permanente cuyo diámetro alcanza 1.2 $\mathrm{km}$. El volcán suele emitir emanaciones de $\mathrm{CO} 2$ por lo que es peligroso y letal para el ser humano. Su última erupción data de 2002. Al norte del volcán se yergue el estrato-volcán Baruta y al sur el estrato-volcán Shaheru. El cráter fue explorado por primera vez por el explorador alemán Adolf Von Gotzen en 1894. La erupción de 1977 precedida por la creación del domo Murara, drenó el lago de lava en menos de una hora produciendo una corriente de lava que se desplazó a $70 \mathrm{~km} / \mathrm{hora}$ haciendo muchísimas víctimas.

\section{EL RIFT EN MALAWI Y MOZAMBIQUE}

El lago Malawi o Nyasa es una prolongación del Gran Rift africano que se extiende por 560 $\mathrm{km}$. con un ancho de $75 \mathrm{~km}$. El espejo de agua se sitúa a $460 \mathrm{~m}$. sobre el nivel del mar. Aquí nos encontramos en el límite de la gran fractura ya que los afloramientos geológicos, tanto del Malawi como del norte del Mozambique se remontan a la era Primaria y Secundaria. Los sectores más recientes son Jurásicos y Cretácicos. El área es una prolongación del cratón del Zimbabwe. Un sector digno de hacer resaltar se sitúa al sur del lago Nyasa en Malawi, donde se encuentra el lago Chilwa 

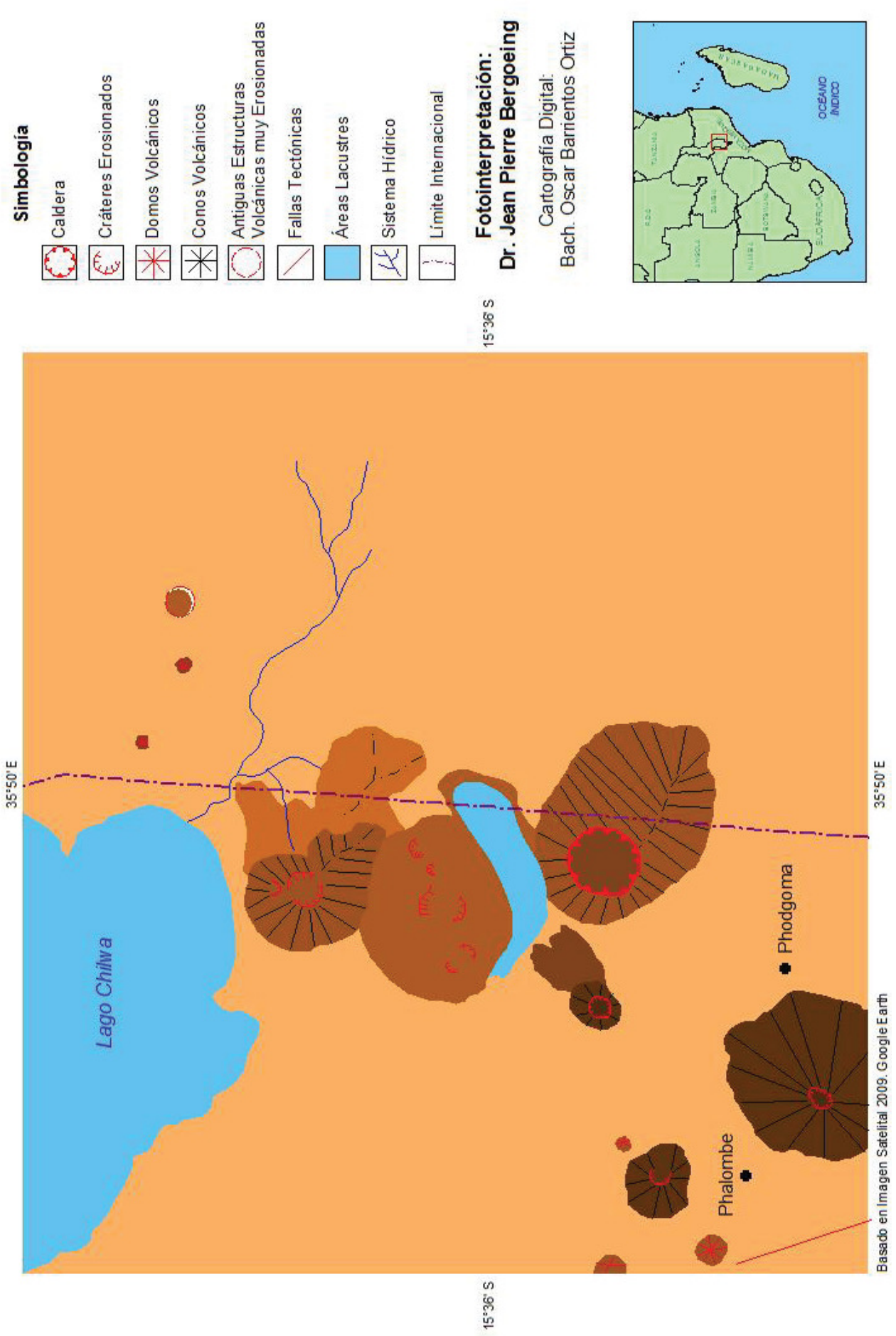

Figura 22 - Lago Chilwa, Malawi Serie de relictos volcánicos del Pleistoceno inferior, que marcan el paisaje lacustre al sury al oeste del lago. (Fotointerpretación basada en imagen satelital Google 2009). 

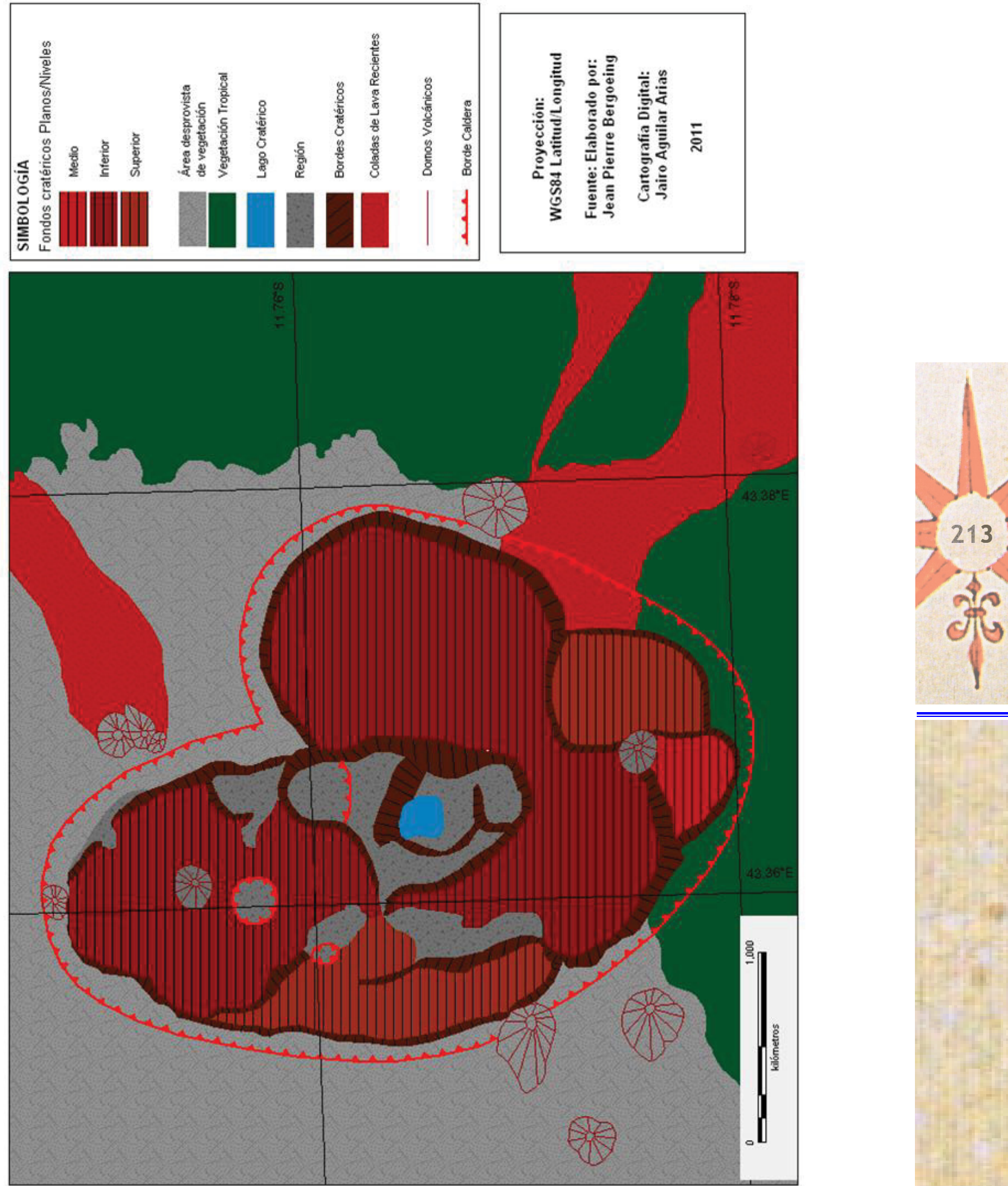

Figura 23 - Caldera del voleán Karthala, en la isla de Gran Comore, archipiélago de las Comores, con sus numerosos cráteres, y al centro el cráter principal con laguna pluvial (Fotointerpretación basada en imagen satelital Google 2011). 
(Figura 22) que ocupa una superficie de $650 \mathrm{~km}^{2}$. Al sur y al oeste del lago quedan los remanentes de un antiguo volcanismo asociado al Gran Rift. En efecto una serie de conos, calderas y cráteres emergen como relictos volcánicos que podrian ser del Pleistoceno inferior ya que para Battistini (Battistini 1968) el Rift Valley en los sectores del lago Nyasa y de la región del Shire ya tenía sus rasgos definitivos a comienzos del Terciario, pero que el gran accidente tectónico que significa la apertura del Rift, va a permitir, en este sector, ascensos magmáticos cuyos testigos son los relictos volcánicos muy erosionados que se observan al sur del lago de Chilwa.

Más al sur el macizo de Mulanje que alcanza los $3.000 \mathrm{~m}$. de altitud y cubre unos $572 \mathrm{~km}^{2}$. Fue descubierto por David Livingstone en 1859. Su presencia se debe a una extrusión granítica del manto a través de la corteza terrestre ocurrida hace unos 130 millones de afios (Cretácico) dando origen a un relieve de inselberg. Este macizo vendría a ser un precursor en la formación del Rift.

En este sector el Rift se introduce y desgarra los afloramientos geológicos antiguos. Al este y oeste del Rift Valley ocupado por el lago Nyasa los bordes están conformados por mesetas antiguas que van de $915 \mathrm{~m}$. a $1220 \mathrm{~m}$ de altitud. En el extremo sur, el lago desagua a través del río Shire para unirse al Zambeze en Mozambique. Al oeste de Mozambique, en la provincia de Tete, fronteriza con Zimbabwe, encontramos el Monte Muambe que es el resultado de un vulcanismo post-caldera del Mesozoico. Se sitúa en la margen sur del río Tete donde aflora un complejo grabro-diorítico del Precámbrico que se entremezcla con el sistema de areniscas del Karroo que se entremezcla con la formación volcánica de Stromberg que son coladas de lavas basálticas y diques de doleritas. A partir del Jurásico inferior y hasta el Cretácico el monte Muambe comienza una extraordinaria actividad volcánica que dará inicia a esta parte del Gran Rift. La caldera de Muambe tiene unos 5 $\mathrm{km}$ de diámetro. (ALFONSO, 1976.)

\section{VOLCÁN KARTHALA, ARCHIPIÉLAGO DE LAS COMORES}

Finalmente debemos incluir en este sistema del Rift el vulcanismo marginal insular representado aquí por el volcán Karthala en la isla de Gran Comore (Figura 23) que forma parte del archipiélago de las Comores.

Es un volcán que ha tenido una gran actividad, con expulsión de lavas basálticas y gases. Su morfología se caracteriza por ser una caldera con varios cráteres en su interior. La isla no es más que la parte emergida de un enorme cono volcánico, separado de Mozambique por el estrecho del mismo nombre. En el estrecho existen conos sumergidos y no por ello menos activos. El volcán Karthala, es un volcán Cuaternario, tiene una elevación de $2.361 \mathrm{~m}$ sobre el nivel del mar, es un volcán escudo y es muy activo. En 2005 y 2006 ha tenido una gran actividad emitiendo gases y cenizas y obligando a evacuar a la población cercana El volcán tiene una historia eruptiva que tiene registros desde el año 1050 . Hay dataciones eruptivas desde 1808 y que se prosiguen en 1814 , $1821,1828,1830,1833,1848,1850,1855,1857,1858,1859,1865,1872,1876,1880,1883,1904$, $1910,1918,1928,1948,1952,1956,1965,1972,1977,1991$, y 2005 al 2007 . Con ello vemos que estamos en presencia de un volcán que tiene actividad continua.

El archipiélago de las Comores al parecer podría ser un sistema lineal de volcanes escudos alcalinos que iría de la Gran Comore hasta el norte de Madagascar bajo el canal de Mozambique y formaria parte de la placa Somali que se estaria separando del Africa a la velocidad de $45 \mathrm{~mm} /$ afio. (Ole Nielsen 2008)

\section{CONCLUSION}

El Gran Rift Africano es uno de los grandes accidentes tectónicos del mundo, que se inicia en el río Jordán, mediante un antiguo accidente tectónico con subidas magmáticas ancestrales y cuyas referencias bíblicas son muy conocidas (Sodoma y Gomorra) para luego contimuar hacia el sur por 
la dorsal del mar Rojo, separando al Africa de la placa tectónica de Arabia y ha dejado sus trazas en ambas márgenes mediante relictos volcánicos basálticos.

El segundo tramo importante es el sector de Eritrea-Etiopia-Yibuti en el continente africano donde grandes depresiones tectónicas ocupadas varias veces por el mar, alternan con más de cincuenta edificios volcánicos de todo tipo que hemos ilustrado brevemente.

Más al sur, en Kenya y Tanzania el Gran Rift se divide en tres grandes sectores dejando a la vista un graben escalonado en donde se han edificado una serie de macizos volcánicos que en Tanzania, superan los 5.000 metros (Kilimanjaro) pero igualmente grandes depresiones lacustres. Los grandes lagos orientales del Africa son una expresión más de esta zona de acreción pudiendo alcanzar profundidades de 1.700 metros.

El accidente tectónico del Gran Rift se continúa con dificultad a través del norte de Mozambique, fracturando los viejos escudos primarios metamórficos. La expresión más reciente de esta fractura se encuentra en el archipiélago de las Comores.

El Gran Rift africano es uno de los accidentes tectónicos N-S más notables del planeta. Es el inicio de la separación de dos masas continentales que en unos millones de afios dará origen a un muevo continente representado por la placa Somali.

No cabe duda que este es un campo de investigaciones en geofisica que puede abarcar cientos de años por cuanto las investigaciones en terreno son muy recientes y parciales, ello debido a la naturaleza tropical o árida de algunos sectores como a los conflictos armados que prevalecen en muchos sectores.

\section{BIBLIOGRAFIA}

AFONSO R S. A Geologia de Moçambique. Maputo: Impresa Nacional de Moçambique, 1976.

AHMED DAOUD, M. Dynamique du rifting continental de $30 \mathrm{Ma}$ à l'Actuel dans la partie Sud-Est du Triangle Afar. Tectonique et magmatisme du rift de Tadjoura et des domaines Danakil et d'Ali Sabieh, République de Djibouti. Thèse présentée pour l'obtention du diplôme de Doctorat. Université de Bretagne Occidentale. France, 2006.

BATTISTINI R. Problemes morphologiques du sud du Malawi. Annales de Geographie $N^{\circ} 422$, vol 77 . pp.431-451. Paris: 1968 .

BART, F. L'Afrique Continent Pluriel. Paris: CNED SEDES, 2003.

BERGER J. P. La chaine d'obduction en Oman et aux Emirats Arabes Unis, 2005- 2011. http:/www. jpb-imagine.com/obductgeol/index.html

BERGOEING J.P. África, Con tinente multifacético. San José: Editorial y Libreria Alma Mater, 2008.

BLANC J.J. 2006. Tourisme Géologique en Egypte: Les déserts, les oasis. Association des anciens et des amis du CNRS. Paris: Edit. Edmond Lisle, 2006.

CHEBET S. \& DIETZ T. Massam - The cliffdwellers of Kenya - Cass. Published by Moi University Press, 2000.

FURON R; LOMBARD J. Carte Géologique de l'Afrique 1 :5.000.000. Paris: UNESCO-ASGA, 1964. GOVERNMENT OF MALAWI. Lake Chilwa wetland state of the environment. Environmental Affairs Department, Lilongwe. Malawi: 2000.

HEMINGWAY, E. The Snows of Kilimanjaro and Other Stories. Scribner, 1995.

JOHANSON, D.; BLAKE, E. From Lucy to Language. New York: Simon \& Schuster, 1996.

JONSSON S.; LU, Z.; LUNDGREN, P. INSAR observations of the 2009 Harrat Lunayyir dike intrusion and post dyking deformations. Geophysical research abstracts, 2009.

KALK, M., MCLACHLAN, A. J.; HOWARD-WILLIAMS, C. (Eds.). Lake Chilwa: studies of change in a tropical ecosystem. London: The Hague Publishers, 1979.

KOSCAL, M.; KACHAMILA, J. M; STEFANOVIC; JANJIC, M. Mineralización de fluorita de Monte Muambe cerbonatite complejo, Mozambique. Resumen de la Segunda Congr. No-Met Minerales pg 
103-114, Beograd, 1985.

LEAKEY, R. E. 1981. The Making of Mankind. New York: E.P. Dutton.

NIELSEN, O. Volcan Karthala, 2008. http:/my.opera.com/nielsol/blog $/ 2008 / 11 / 20 / \mathrm{karthala-volcano-on-}$ -grand-comoro

NONNOTTE $P h$. Etude volcano-tectonique de la zone de divergence nord tanzanienne (terminaison sud du Rift Kenyan). Caractérisation pétrologique et géochimique du volcanisme récent (8 M.a. - Actuel) et du manteau de source. Contraintes de mise en place. Thèse de Doctorat. Université de Bretagne Occidentale. Géosciences Marines, 2007.

PAVITT, N. Africa's Great Rift Valley. New York: Harry N. Abrams, 2001.

POWERS D. W. Geology of Mio-Pliocene sediments of the Lower Kerio River Valley, Kenya. USA: Princeton University, 1980.

STEDMAN, H. Kilimanjaro: A Guide to Climbing Africa's Highest Mountain, Includes City Guides to Arusha, Moshi, Marangu, Nairobi and Dar Es Salaam. Trailblazer Publications, 2003.

RIDGEWAY, R. The Shadow of Kilimanjaro. Owl Books: 1999.

WRIGTH ,H. E.; KUTZBACH, J. E.; WEB, T.; RUDDIMAN, W. F.; STREET PERROT, F. A.; BARTLEIN P J. Global Climates since the last glacial maximum. University of Minnesota Press: 1993.

Trabalho enviado em novembro de 2012 Trabalho aceito em dezembro de 2012 